\title{
Flexural behavior of bamboo-concrete composite beams with perforated steel plate connections
}

\author{
Zhiyuan Wang ${ }^{1,2}$, Yang Wei ${ }^{i^{*}}$, Ning $\mathrm{Li}^{1}$, Kang Zhao ${ }^{1}$ and Mingmin Ding ${ }^{1}$
}

\begin{abstract}
A new type of bamboo-concrete composite structure using perforated steel plates as connectors was proposed. To study the composite effect of this new type of composite structure, the slip behavior of bamboo-concrete shear connectors was first studied through push-out tests. Subsequently, four-point bending tests of ten bamboo-concrete composite beams were carried out. The results show that the failure of bamboo-concrete shear connectors occurred between the perforated steel plate and the concrete, and there was no obvious damage between the perforated steel plate and the bamboo. The load carrying capacity of perforated steel plate connectors was relatively stable. The failure mode was moderate failure. Considering the three stages of the load-slip curve, an exponential function is proposed to describe the load-slip curve. The failure modes of composite beams can be summarized as two types. In the first type, the bamboo beam ruptures on the bottom and the concrete dose not suffer significant damage; in the second type, the top surface of the concrete first exhibits longitudinal cracks, and finally, the bamboo beam ruptures. Compared with bamboo beams, the ultimate load of composite beams increased by 1.2-1.5 times, and the sectional stiffness of composite beams increased by 2.9-4.2 times. The equivalent section stiffness was obtained after determining the connection coefficient, and the connection coefficient $\gamma_{b}$ ranged between 0.50 and 0.80 and decreased as the center spacing of the perforated steel plate increased. The equivalent cross-section stiffness obtained by different load stages of the shear slip stiffness was calculated to predict the mid-span displacement. The calculation results show that the effect of slip stiffness on the equivalent stiffness of cross section is not sensitive, and a $35 \%$ increase in slip stiffness results in a maximum increase in equivalent section stiffness of only $6 \%$.
\end{abstract}

Keywords: Bamboo, Bamboo-concrete, Composite structure, Perforated steel plate, Equivalent section stiffness, Composite effect

\section{Introduction}

Green, environmentally friendly, ecological, low-carbon and sustainable new materials are being actively explored for application in the field of civil engineering $[1,2]$. Bamboo and wood are typical sustainable materials. Bamboo, with outstanding advantages including short growth cycle, high strength and low cost of cultivation, has become increasingly popular as a renewable structural

\footnotetext{
*Correspondence: wy78@njfu.edu.cn

'School of Civil Engineering, Nanjing Forestry University, Nanjing 210037, People's Republic of China

Full list of author information is available at the end of the article
}

material in recent decades because of the shortage of timber in the international market $[3,4]$. The application of raw bamboo in civil engineering includes bamboo towers, bamboo buildings [5], bamboo-reinforced concrete [6-9], etc. However, the shape of bamboo is that of an irregular thin-walled elliptical cone tube, which has low carrying capacity and large discreteness of mechanical properties, making it difficult to meet the structural requirements of many engineering structures $[10,11]$. To make more effective use of bamboo, many engineering bamboo materials, such as bamboo scrimber [12], laminated bamboo [13] and bamboo glulam [14, 15], have been developed, studied and utilized. Existing research 
shows that using bamboo engineering materials as flexural members have some unfavorable aspects, such as low section stiffness and insufficient bearing and spanning capacity. In light of the research on timber-concrete and steel-concrete composite structures [16-20], bamboo-steel composite structures [21-23] and bamboo-concrete composite structures [24-28] have been proposed and explored to further improve the overall mechanical performance of engineering bamboo and other engineering materials [29-31]. To explore a more effective and reliable combination mode, a new type of bamboo-concrete composite structure using perforated steel plates as connectors was proposed. To study the composite effect of this new type of composite structure, the shear behavior of bamboo-concrete shear connectors is examined, and then a four-point bending test of composite beams is carried out to study the loading process, the strain variation and distribution of the mid-span section, and the slip law of the interface.

\section{Materials and methods Material properties}

The shear connectors and composite beams were made of the same materials, including bamboo scrimber, concrete and perforated steel plates. Bamboo scrimber is a new material formed by reorganizing and strengthening bamboo. In detail, bamboo is processed into strips of bamboo, i.e., bamboo fiber; impregnated after drying; dried to the required moisture content; laid and pressed in a mold; and finally cured by high-temperature and high-pressure heat.

Referencing ASTM D143-09 "standard test methods for small clear specimens of timber" [32] to determine the mechanical properties of bamboo scrimber, 12 tensile specimens $(25 \times 10 \times 455 \mathrm{~mm})$ and 12 compressive specimens $(50 \times 50 \times 150 \mathrm{~mm})$ were prepared and tested. Based on the test results, the ultimate tensile strength $\left(f_{\mathrm{bt}}\right)$, ultimate compressive strength $\left(f_{\mathrm{bc}}\right)$, and elastic modulus of bamboo scrimber were $149.46 \mathrm{MPa}$ $(\mathrm{SD}=9.97, \mathrm{COV}=6.7 \%), 90.1 \mathrm{MPa}(\mathrm{SD}=5.1, \mathrm{COV}=6 \%)$ and 17.4 $\mathrm{GPa}(\mathrm{SD}=0.93, \mathrm{COV}=5.8 \%)$, respectively. The mix ratio of fine aggregate concrete for the test was 1:0.4066:1.33:2.649 (cement:water:sand:stone). The average compressive strength of concrete cubes $(150 \times 150 \times 150 \mathrm{~mm})$ and cylinders $(\phi 150 \times 300 \mathrm{~mm})$ were $45.4 \mathrm{MPa}$ and $35.6 \mathrm{MPa}$ at the time of testing, respectively, and the elastic modulus was $28.2 \mathrm{GPa}$. The yield strength and elastic modulus of the steel plates were 253.4 MPa and 197.8 GPa, respectively. The yield strength and elastic modulus of $6 \mathrm{~mm}$ steel bars used as constructional reinforcement for specimens were $550.5 \mathrm{MPa}$ and $171.9 \mathrm{GPa}$.

\section{Shear connectors}

For the mechanical analysis of bamboo-concrete composite beams, the mechanical properties of shear connectors must be identified in advance. Referring to EN 26,891, three specimens of shear connectors with the same parameters were designed. The specimens are designated as P1, P2 and P3. The specimens consists of one bamboo block $(140 \times 350 \times 70 \mathrm{~mm})$ and two concrete blocks $(140 \times 350 \times 70 \mathrm{~mm})$, as shown in Fig. 1 . The bamboo slabs were located in the middle of the specimens, the concrete slabs were symmetrically arranged on both sides of the slab, and the two different parts were connected with the perforated steel plate connectors (Fig. 1a). The size of the perforated steel plate was $100 \times 100 \times 2 \mathrm{~mm}$ (Fig. 1b). The perforated steel plates were arranged in the middle part of the interface of the two sides. The depths of the steel plates embedded in bamboo and concrete were $60 \mathrm{~mm}$ and $40 \mathrm{~mm}$, respectively. The concrete is strengthened by the steel bars in both longitudinal and transverse directions near the interface, and the steel bars are not connected with the steel plates to avoid possible complex interactions. During the preparation of the specimen, the steel plate was embedded in the pre-opened seam of the bamboo board through adhesive, and the exposed part was poured in the concrete to form a whole. Considering the difference between concrete and epoxy adhesive, circular holes with diameters of $25 \mathrm{~mm}$ and $10 \mathrm{~mm}$ were set on the steel plate of the concrete section and bamboo section, respectively, to improve the connection performance.

An electrohydraulic testing machine with a maximum loading force of $3000 \mathrm{kN}$ was used in the test. To eliminate the influence of gaps between components of specimens and confirm that the loading device was working properly, pre-loading (with a $5-\mathrm{kN}$ load) was carried out before formal loading. The displacement control was adopted in the formal test, and the loading speed was $1 \mathrm{~mm} / \mathrm{min}$, which was changed to $0.5 \mathrm{~mm} /$ min when approaching failure until the specimen failed. The interface slip was measured by two methods: The first method used a linear variable displacement transducer (LVDT). Three displacement transducers were arranged at the interface on both sides of each specimen to measure the interface slip at the bottom, middle and top of the specimen. The displacement meter was fixed on the concrete plate, and the measuring rod was fixed on the bamboo plate at the same level (Fig. 2a). The second method used digital image correlation (DIC). The equipment and software are provided by the Correlated Solution Company in the United States. The camera focal length for the equipment is $25 \mathrm{~mm}$, the focal resolution is 12 million, and the displacement measurement resolution is $1 \%$. The software of VIC-3D 


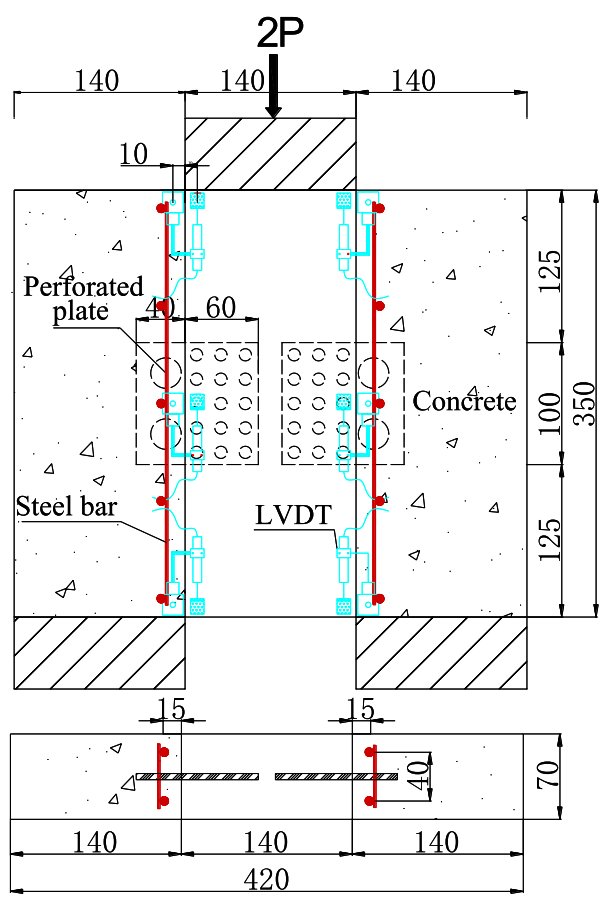

a Shear connectors

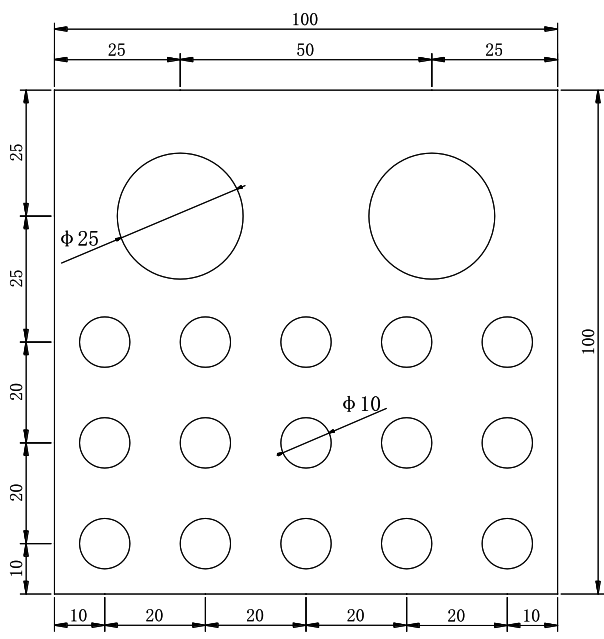

b Perforated steel plate

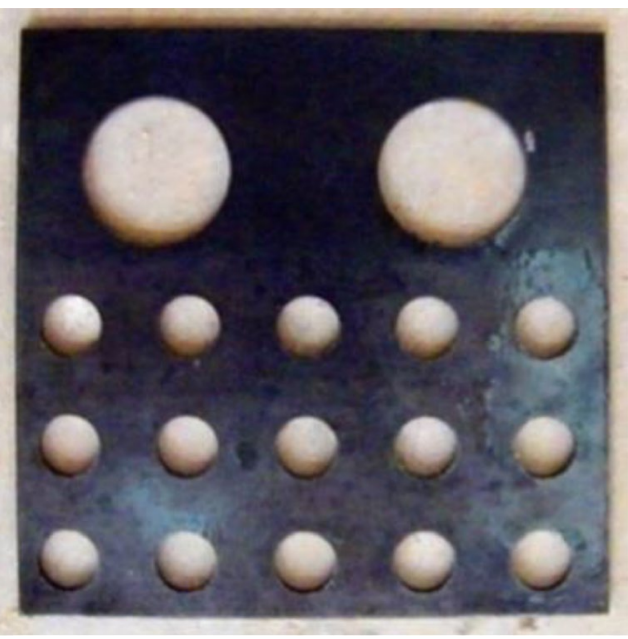

c Photographs of perforated steel plates

Fig. 1 Details of the push-out test and perforated steel plate (units: $\mathrm{mm}$ )

is employed. After polishing and cleaning the surface of concrete and bamboo of the specimens, a layer of white matte paint was sprayed first on the surface, and then black paint was sprayed to form uniformly distributed black spots. Then, two image collectors were used to continuously collect the deformation images of the specimens during the entire test process, with the data being collected every $3 \mathrm{~s}$. In this test, 12 points were selected symmetrically along the interface of bamboo and concrete. After calculation, the relative slip of the interface in the entire field was obtained (Fig. 2b).

\section{Composite beams}

Two bamboo beam specimens and ten bamboo-concrete composite beam specimens with perforated steel plate connections were manufactured in this test. Every two specimens with the same parameters were one group, as shown in Table 1 . The bamboo beam used as the 


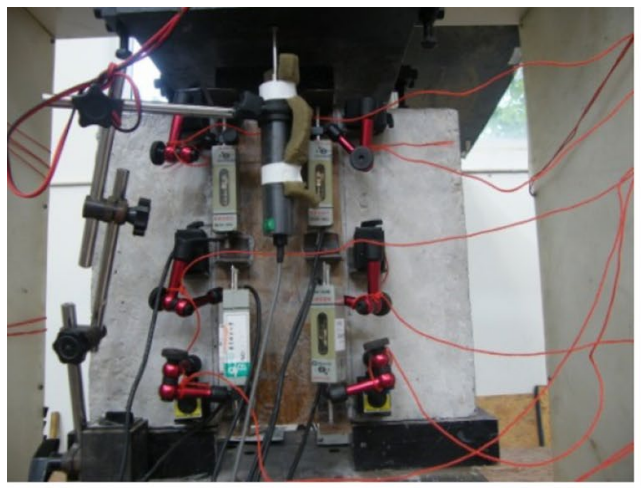

a LVDT setup

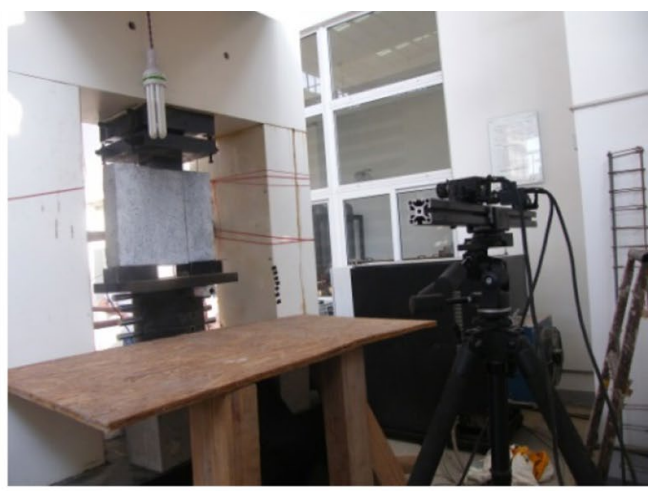

b DIC setup

Fig. 2 Loading and testing setup for the push-out test

Table 1 Parameters of beam specimens

\begin{tabular}{|c|c|c|c|c|c|c|c|c|c|}
\hline \multirow[t]{2}{*}{ Group } & \multirow[t]{2}{*}{ Specimen } & \multicolumn{2}{|l|}{ Concrete } & \multicolumn{2}{|l|}{ Bamboo } & \multirow[t]{2}{*}{ Section shape } & \multicolumn{2}{|c|}{ Connectors } & \multirow{2}{*}{$\begin{array}{l}\text { Number } \\
\text { of specimens }\end{array}$} \\
\hline & & Width (mm) & Height (mm) & Width (mm) & Height (mm) & & Number & Spacing (mm) & \\
\hline BO & B0-1/B0-2 & - & - & 70 & 140 & Rectangular & - & - & 2 \\
\hline BP100 & BP100-1/BP100-2 & 200 & 50 & 70 & 140 & T shape & 25 & 100 & 2 \\
\hline BP150 & BP150-1/BP150-2 & 200 & 50 & 70 & 140 & Tshape & 16 & 150 & 2 \\
\hline BP200 & BP200-1/BP200-2 & 200 & 50 & 70 & 140 & Tshape & 12 & 200 & 2 \\
\hline BP250 & BP250-1/BP250-2 & 200 & 50 & 70 & 140 & T shape & 10 & 250 & 2 \\
\hline ВР300 & ВР300-1/ВР300-2 & 200 & 50 & 70 & 140 & T shape & 8 & 300 & 2 \\
\hline
\end{tabular}

benchmark was group B0, and the composite beams were divided into five groups according to the central spacing of the perforated steel plate: 100, 150, 200, 250 and $300 \mathrm{~mm}$, numbered as group BP100, group BP150, group BP200, group BP250 and group BP300, respectively. The section shape of composite beams was T-shaped, with bamboo in the bottom part and concrete in the top part. The size of the bamboo beams was $70 \times 140 \times 2500 \mathrm{~mm}$, and the size of concrete was $200 \times 50 \times 2500 \mathrm{~mm}$ (Fig. 3). In the process of specimen manufacturing, the longitudinal seam was first opened on the top surface of the bamboo beam. The depth of the longitudinal seam was $60 \mathrm{~mm}$, and the width was $2.5 \mathrm{~mm}$. Then, the formwork was built according to the size of the upper concrete slab, and the constructional reinforcement was assembled. Then, the $100 \times 100 \times 2 \mathrm{~mm}$ perforated steel plate was embedded into the pre-opened seam of the bamboo beam with epoxy resin at different interval spacings. The depth of the steel plate embedded in the bamboo was $60 \mathrm{~mm}$, and the height of exposed bamboo in the upper part was $40 \mathrm{~mm}$. After the epoxy resin was cured, concrete was mixed and poured. Finally, the finished specimens were obtained by removing the formwork after curing (Fig. 4).
Four-point bending loading was adopted in the test. The specimens were placed and loaded symmetrically in the middle, the total length of the specimens was $2500 \mathrm{~mm}$, the distance between the centerlines of the two supports was $2400 \mathrm{~mm}$, and the distance between the two loading points in the middle was $800 \mathrm{~mm}$ (Fig. 5a). Before loading, the specimen was preloaded to check whether the instrument was working properly and eliminate any poor contact. The displacement control method was adopted during the loading process, and the loading speed was $2 \mathrm{~mm} / \mathrm{min}$.

Three vertical displacement transducers were arranged at the mid-span and two supports of the specimen to measure the vertical displacement at the mid-span and the support, respectively. To measure the relative slip distribution of the interface between concrete and bamboo, six relative displacement transducers D1, D2, D3, D4, D5 and D6 were arranged along the interface between bamboo and concrete in the mid-span of the specimen. The displacement meter base was placed on the concrete, and the measuring rod was fixed on the bamboo plate at the same position. To measure the strain distribution in the mid-span section of the specimen, strain gauges were pasted on the top, bottom and side of the specimen 


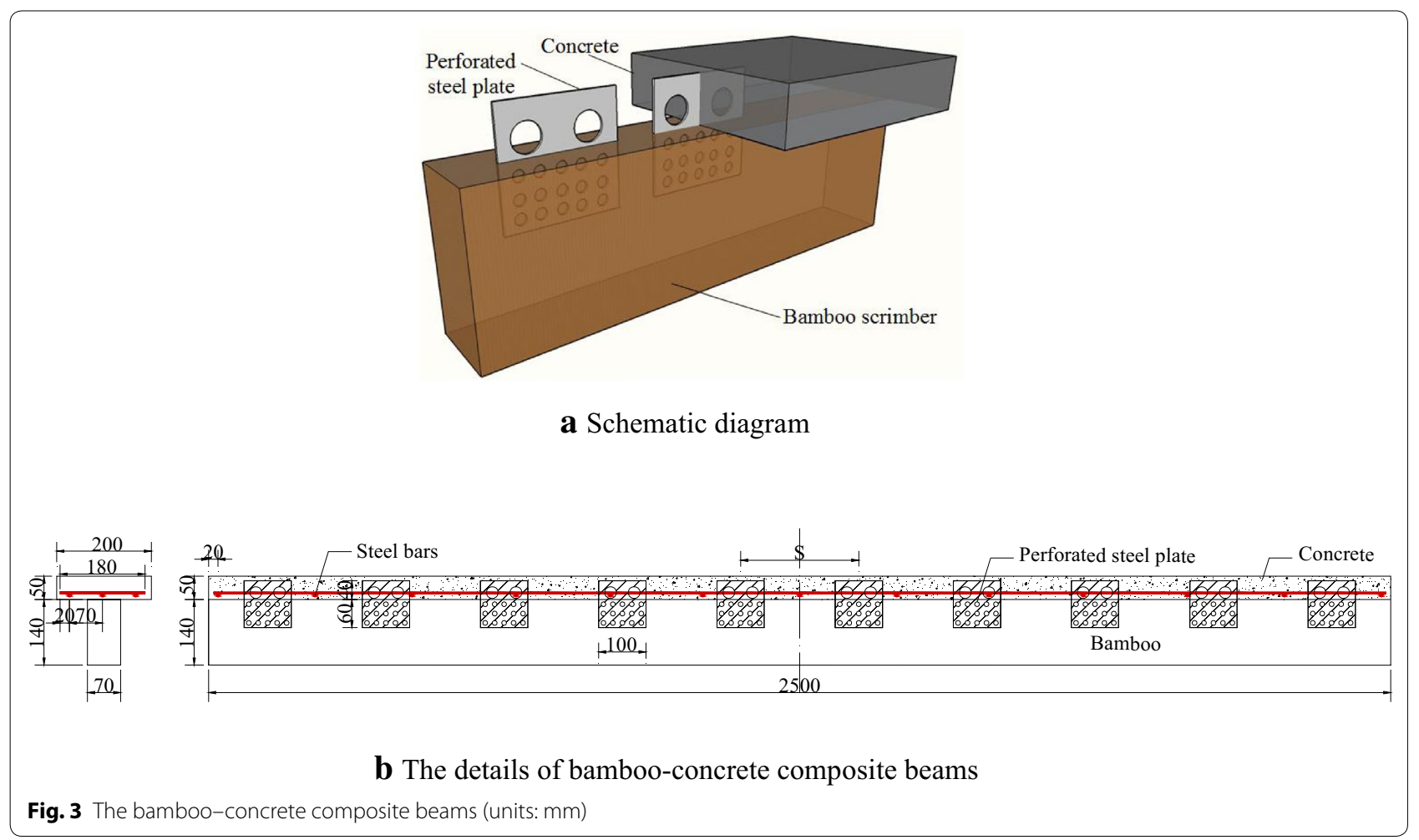

(Fig. 5b). The strain gauges pasted at the top and bottom of the bamboo beams were numbered B1, B2, B7 and B8, and the strain gauges arranged on the side of the bamboo beams with spacings of $28 \mathrm{~mm}$ were numbered B3, B4, B5 and B6. The strain gauges on the top surface of the concrete were numbered $\mathrm{C} 1$ and $\mathrm{C} 2$, and the strain gauges on the flange side of the concrete pasted with spacings of $15 \mathrm{~mm}$ were numbered C3-C5. A strain gauge named C6 was attached to the bottom of the concrete slab near the interface of the concrete and bamboo beams. The strain gauges on the surface of the internal steel bars were numbered S1-S3.

\section{Results and discussion Shear connectors Failure modes}

The typical failure modes of the shear connector specimens are shown in Fig. 6. When the load value was less than $60 \%$ of the ultimate load in the early stage of loading, there was no obvious failure; only slight cracks were gradually formed at the interface between the bamboo and the concrete, the slip of the interface was extremely small, and the slip stiffness was relatively high. When the load value reached approximately $60-70 \%$ of the ultimate load, the inclined cracks extended downward from the middle part of the concrete, and then partial concrete peeling occurred on surfaces. When the load value reached approximately $70-100 \%$ of the ultimate load, the relative slip of the interface between the bamboo and the concrete can be identified on the top or bottom end (slip at the ultimate load is between 0.40 and $1.34 \mathrm{~mm}$ ). After the ultimate load, the relative slip increased sharply. There was no significant vertical separation between the bamboo and the concrete. With the increase of the slip, the load value decreased gradually. After the test, the concrete part was chiseled out, and the various components of the specimens, including the perforated steel plate, were observed. It was found that the bond between the perforated steel plate and bamboo was intact, shear failure mainly occurred between the perforated steel plate and concrete, and the steel plate showed a large plastic deformation along the loading direction. At the same time, the concrete shear tenons in the holes of the perforated steel plate were completely fractured due to shear, and the concrete supporting surface at the bottom of the steel plate was crushed completely. The relative slip in the loading stage of the shear connector specimens mainly occurred between the perforated steel sheet and the concrete. In general, the specimens could withstand a high load and suffer a large plastic deformation during the entire loading process, so the failure mode of the shear connectors connected with the perforated steel plate may attributable to moderate failure. 


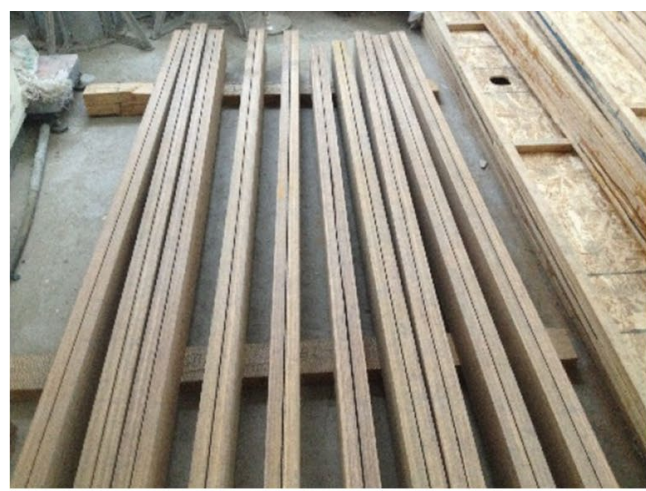

a Opening longitudinal seam

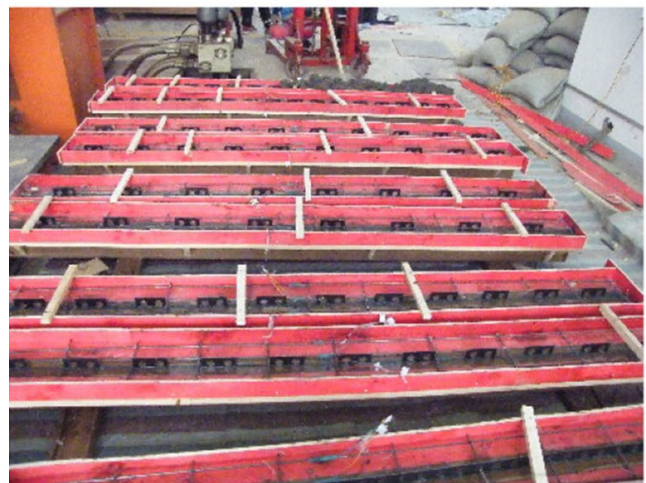

c Embedding perforated steel plates

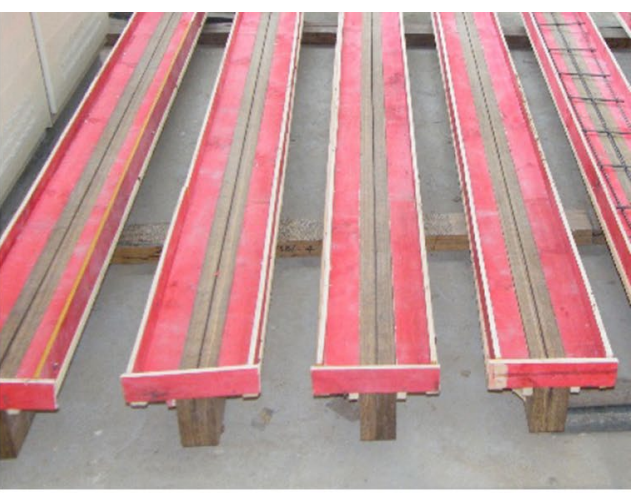

b Setting formwork

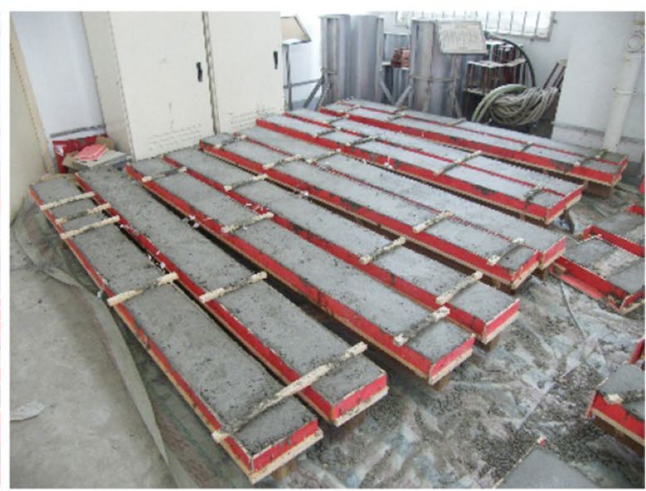

d Pouring concrete

Fig. 4 Manufacturing process of composite beams

\section{Load-slip curves}

The load-slip curves at the representative positions of the perforated plate connections of bamboo-concrete are shown in Fig. 7. Because the right and left connectors are symmetrically connected, the total load has been divided by two to obtain the mechanical properties of an individual connector. The overall trends of the curves measured by LVDT and DIC were basically the same. The load-slip curve can be divided into three stages. The first stage (0-70\% ultimate load) was the elastic stage, and the load-slip curve was basically linear with the increase of load. The perforated steel plate and bamboo were well bonded. The concrete shear tenon in the steel plate hole and the concrete supporting surface at the bottom of the steel plate provided effective shear transfer. Slip between bamboo and concrete developed slowly and steadily. The second stage $(70-100 \%$ ultimate load) was the elastic-plastic stage. The increase rate of the interface slip was obviously accelerated, and the load-slip relationship was nonlinear. The concrete tenon in the hole of the perforated steel plate failed due to shear. The third stage was the descending stage. The load decreased slowly and the slip increased rapidly until the specimen failed. Because the slip value could not be calculated by DIC after concrete peeled off the specimen surface, the ultimate slip value obtained by this method was relatively small. The overall trends of the curves measured by DIC and LVDT were basically similar, taking specimen $\mathrm{P} 1$ as an example, the slip at the ultimate load only differs by $0.01 \mathrm{~mm}$, with an error of $2.1 \%$. The DIC method can effectively measure the relative slip of bambooconcrete shear connectors. Figure 8 shows the relative slip of specimen P3 as an example, it can be observed that the slip is uniformly distributed along the height in both sides for the perforated plate shear connections and the shear transmits evenly.

The test results of each specimen are shown in Table 2. Shear stiffness $K$ (Formula 1 ) is an important index for evaluating the connection performance of shear connectors. To reflect the shear stiffness of shear connectors at different loading stages, the slip stiffnesses corresponding to 40,60 and $80 \%$ of the ultimate load $\left(P_{\mathrm{u}}\right)$ are defined as $K_{\mathrm{s}, 0.4}, K_{\mathrm{s}, 0.6}$ and $K_{\mathrm{s}, 0.8}$ to match the serviceability limit state, 


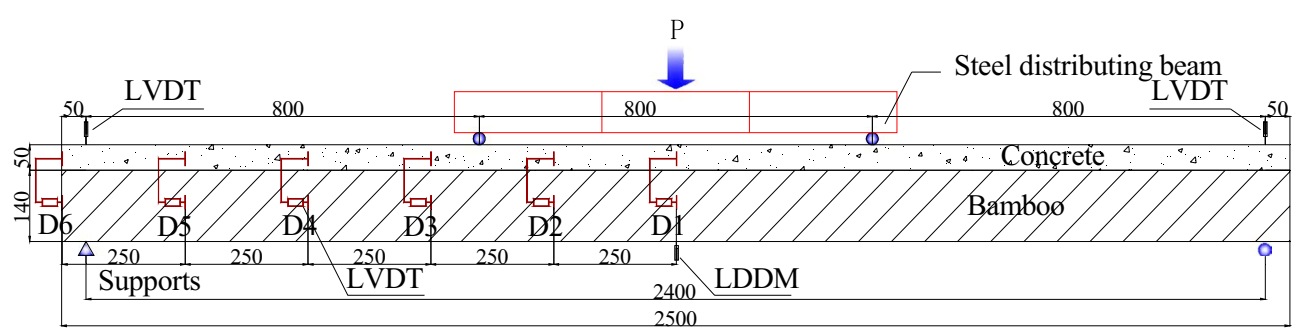

a Loading setup
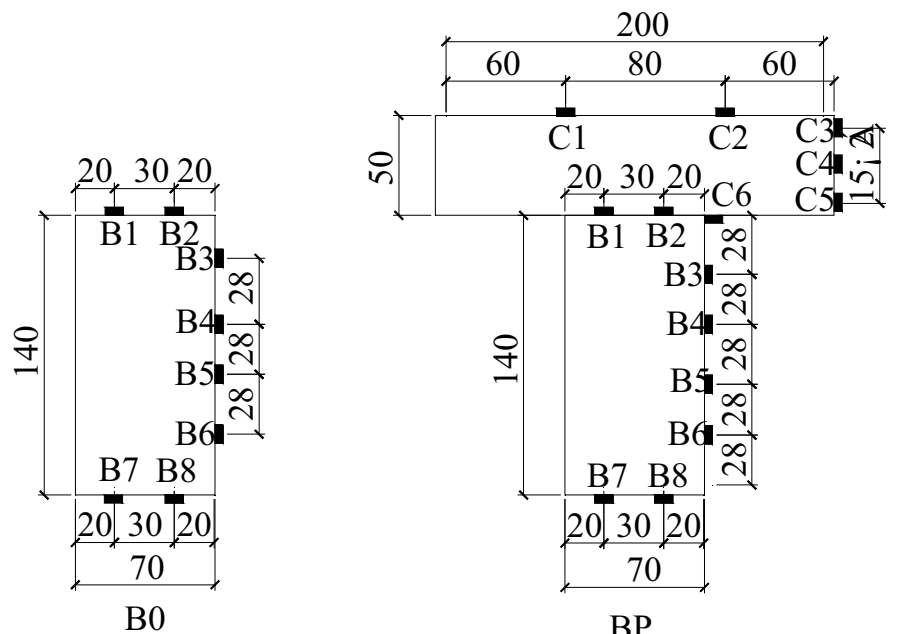

b Strain gauge layout

Fig. 5 Loading setup and strain gauges layout of beam specimens (units: $\mathrm{mm}$ )

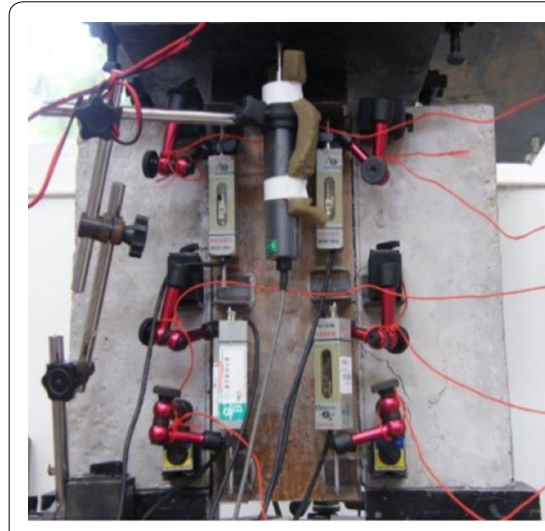

a Concrete cracks

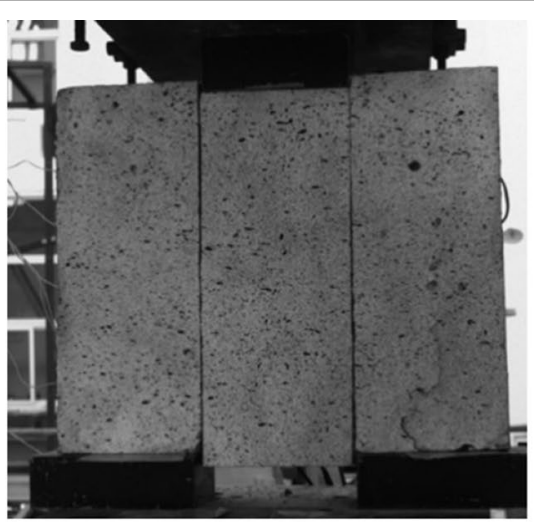

b Interface slip

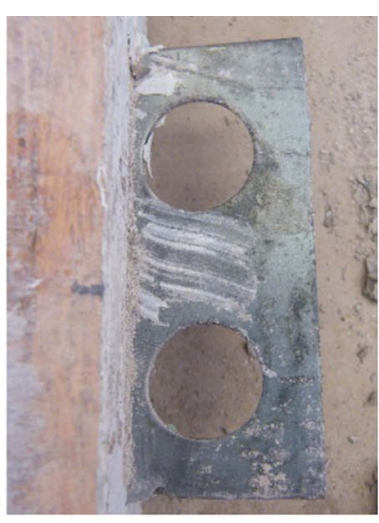

c Deformation of perforated steel plate

Fig. 6 Failure modes of perforated plate connections of bamboo-concrete (P1)

ultimate limit state and critical failure. The ductility coefficient $D$ is defined to quantitatively describe the working ductility of shear connectors [12]:

$$
K=P / S,
$$

$$
D=S_{\mathrm{u}} / S_{\mathrm{y}},
$$

where $K$ is the shear slip stiffness of the connector, $\mathrm{kN} \mathrm{mm}^{-1} ; P$ is the load value, $\mathrm{kN} ; S$ is the slip value, $\mathrm{mm}$; $S_{\mathrm{u}}$ is the slip value when the corresponding load drops to 


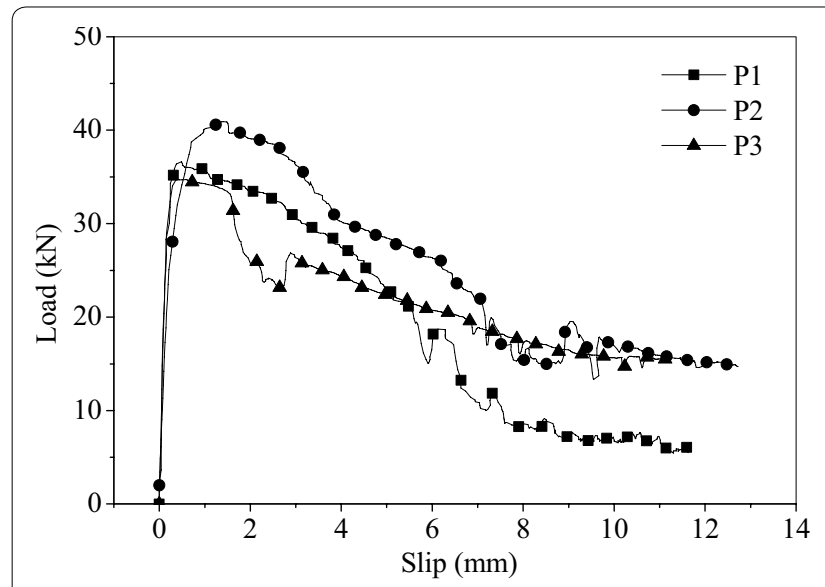

a Measured curves by LVDT

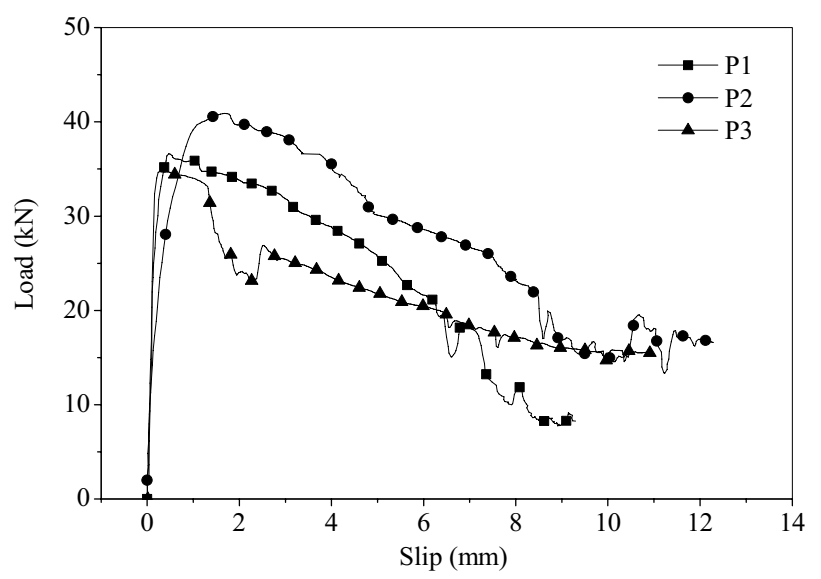

b Measured curves by DIC

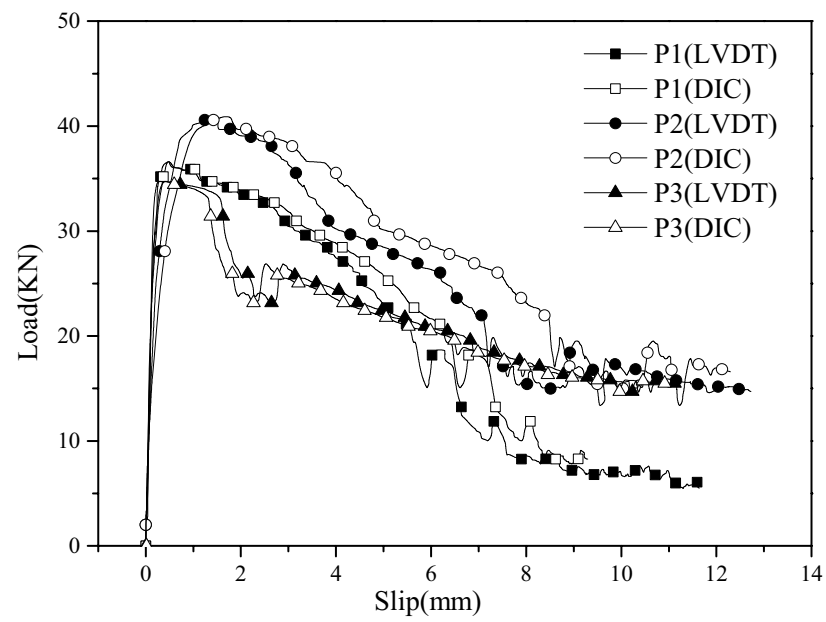

c Measured curves by LVDT and DIC

Fig. 7 The load-slip curves of perforated plate connections of bamboo-concrete

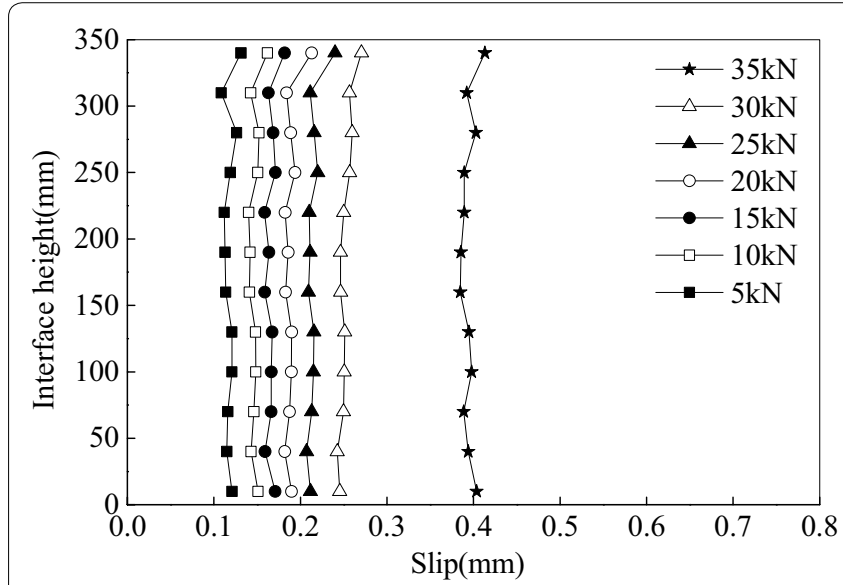

a Left interface

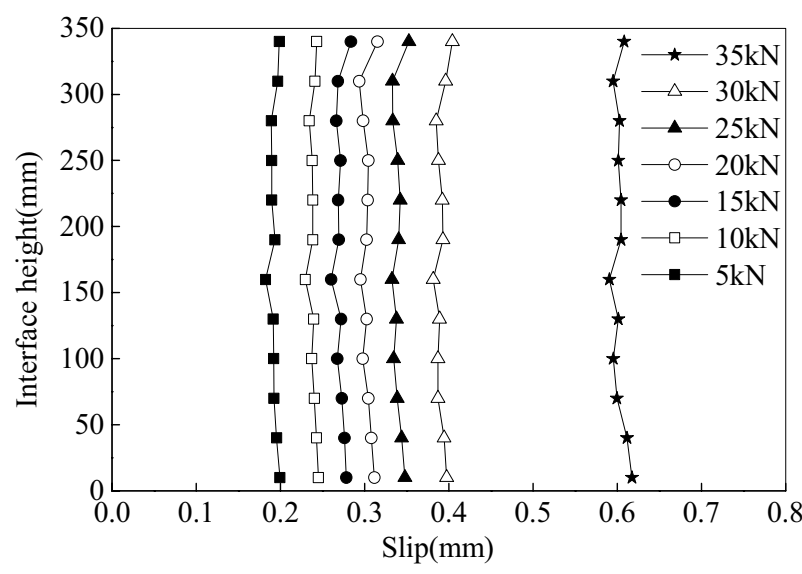

b Right interface

Fig. 8 The curves of slip of bamboo-concrete connections along interface height (P3) 
Table 2 Test results of perforated plate connections of bamboo-concrete

\begin{tabular}{|c|c|c|c|c|c|c|c|c|c|}
\hline Test method & $\begin{array}{l}\text { Specimen } \\
\text { number }\end{array}$ & $\begin{array}{l}\text { Ultimate load } \\
P_{\mathrm{u}} / \mathrm{kN}\end{array}$ & $\begin{array}{l}\text { Ultimate slip } \\
S_{0} / \mathrm{mm}\end{array}$ & $K_{\mathrm{s}, 0.4} / \mathrm{kN} / \mathrm{mm}$ & $K_{\mathrm{s}, 0.6} / \mathrm{kN} / \mathrm{mm}$ & $K_{\mathrm{s}, 0.8} / \mathrm{kN} / \mathrm{mm}$ & $\mathrm{S}_{\mathrm{u}} / \mathrm{mm}$ & $\mathrm{S}_{\mathrm{y}} / \mathrm{mm}$ & $D$ \\
\hline \multirow[t]{6}{*}{ LVDT } & P1 & 36.63 & 0.48 & 222.00 & 183.15 & 162.80 & 3.48 & 0.18 & 19.33 \\
\hline & P2 & 40.91 & 1.34 & 136.37 & 122.73 & 74.38 & 3.60 & 0.44 & 8.18 \\
\hline & P3 & 34.75 & 0.40 & 231.67 & 208.50 & 198.57 & 1.79 & 0.14 & 12.79 \\
\hline & AVE & 37.43 & 0.74 & 196.68 & 171.46 & 145.25 & 2.96 & 0.25 & 13.43 \\
\hline & SD & 3.16 & 0.52 & 52.46 & 44.07 & 63.93 & 1.01 & 0.16 & 5.60 \\
\hline & COV & 0.08 & 0.70 & 0.27 & 0.26 & 0.44 & 0.34 & 0.65 & 0.42 \\
\hline \multirow[t]{6}{*}{ DIC } & P1 & 36.63 & 0.47 & 218.69 & 199.80 & 139.55 & 3.83 & 0.21 & 18.24 \\
\hline & P2 & 40.91 & 1.70 & 116.89 & 79.18 & 54.55 & 4.58 & 0.6 & 7.63 \\
\hline & P3 & 34.75 & 0.28 & 239.66 & 221.81 & 213.85 & 1.51 & 0.13 & 11.62 \\
\hline & AVE & 37.43 & 0.82 & 191.74 & 166.93 & 135.98 & 3.31 & 0.31 & 12.50 \\
\hline & SD & 3.16 & 0.77 & 65.67 & 76.79 & 79.71 & 1.60 & 0.25 & 5.36 \\
\hline & COV & 0.08 & 0.94 & 0.34 & 0.46 & 0.59 & 0.48 & 0.81 & 0.43 \\
\hline
\end{tabular}

The data in the table are calculated based on the displacement data measured by the displacement meter in the middle of the specimen and the black spot displacement data at the corresponding position

$80 \%$ of the ultimate load $P_{\mathrm{u}}, \mathrm{mm}$; and $S_{\mathrm{y}}$ is the slip value when the corresponding load rises to $80 \%$ of the ultimate $\operatorname{load} P_{\mathrm{u}}, \mathrm{mm}$.

Table 2 shows the shear stiffnesses $K_{\mathrm{s}, 0.4}, K_{\mathrm{s}, 0.6}$, and $K_{\mathrm{s}, 0.8}$ at different loading stages. Due to a slight local failure occurred near the connector of P2 specimen in the early stage of loading, which caused relatively smaller shear stiffness than specimens P1 and P3 before the peak load. The average calculated results by LVDT are 196.68, 171.46 , and $145.25 \mathrm{kN} / \mathrm{mm}$, respectively. The average calculated results by DIC are 191.74, 166.93 and $135.98 \mathrm{kN} /$ $\mathrm{mm}$. The data obtained by the two methods are comparatively consistent. Shear stiffness is relatively stable and decreases slowly. Table 2 shows that the average ultimate bearing capacity of shear connectors is $37.43 \mathrm{kN}$, the standard deviation is small, and the coefficient of variation is only 0.08 , which indicates that the load carrying capacity of shear connectors with perforated steel plates is relatively stable. The ductility coefficient calculated by LVDT is $8.18-19.33$, the ductility coefficient calculated by DIC is $7.63-18.24$, and the overall average ductility coefficient is approximately 13.0. The specimens showed excellent slip deformation ability.

\section{Load-slip model of shear connectors}

The test results of load-slip curves of shear connectors show that the load-slip curves consist of elastic, elasticplastic and fully plastic stages during the loading process (Fig. 9). Therefore, the load-slip curve model describing this process should contain these three distinct characteristics. In this paper, Formula 3 is proposed to describe this feature:

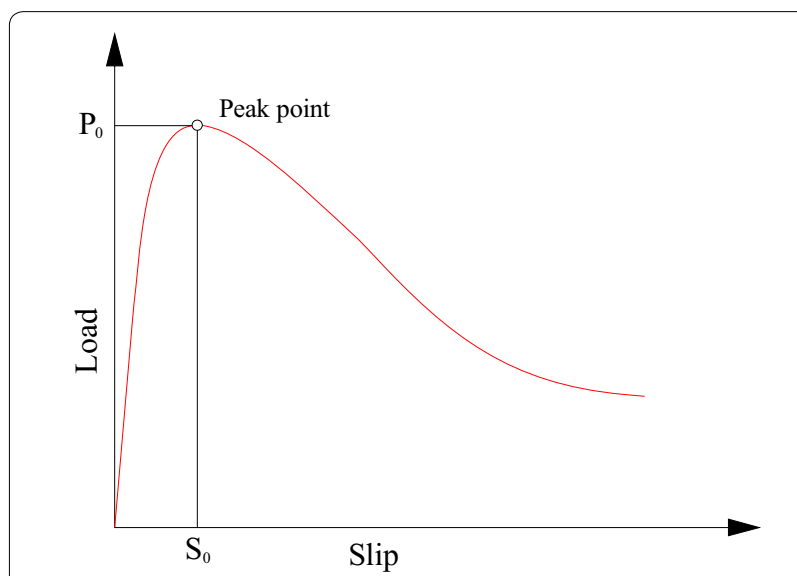

Fig. 9 Load-slip curve of shear connectors calculated by the proposed model

$$
\frac{P}{P_{0}}=c\left[\exp \left(a \frac{S}{S_{0}}\right)-\exp \left(b \frac{S}{S_{0}}\right)\right]
$$

where $P_{0}$ is the peak load value, $\mathrm{kN} ; S_{0}$ is the interface slip value corresponding to the peak load, $\mathrm{mm}$; and $a, b$, and $c$ are the constants determined according to the test results. Formula 3, as a simple and continuous expression, can simultaneously describe three stages of the load-slip curve: elasticity, elastic-plasticity and complete plasticity.

According to the boundary conditions, the following expressions can be obtained:

$$
f^{\prime}(0)=\left.\frac{\mathrm{d}\left(p / p_{0}\right)}{\mathrm{d}\left(s / s_{0}\right)}\right|_{x=0}=c(a-b)=K_{\mathrm{i}} / K_{\mathrm{sec}}
$$


where $P$ is the vertical load, $\mathrm{kN} ; S$ is the interface slip between bamboo and concrete, $\mathrm{mm}$; and $K_{i}$ and $K_{\mathrm{sec}}$ are the tangent stiffness of the load-slip curve at the origin (approximate slip stiffness $K_{\mathrm{s}, 0.4}$ ) and secant stiffness at the peak load, $\mathrm{kN} / \mathrm{mm}$, respectively.

For the perforated steel plate bamboo-concrete connector, according to the test results, it is suggested that $a=-0.08$ and $\mathrm{c}=1.13$. In Formula (4), the expression of $b$ can be obtained by ignoring $a$ because its value is very small compared to that of $b$ :

$$
-c \cdot b=K_{\mathrm{i}} / K_{\mathrm{sec}} .
$$

The test specimens in this paper are calculated according to the load-slip model (Formulas (3)-(5)) of the shear connectors recommended in this paper. The values of $b$ can be calculated from Formulas (3)-(5) according to the test data. The values of $b$ corresponding to specimens $\mathrm{P} 1, \mathrm{P} 2$ and $\mathrm{P} 3$ are $-2.91,-4.45$ and -2.67 , respectively. Comparing the predicted curve from calculations with the experimental curve, as shown in Fig. 10, it can be seen that the load-slip curve is in good agreement with the experimental curve. The load-slip model of the shear connectors proposed in this paper can be used for detailed numerical analysis of the entire loading process of bamboo-concrete composite structures connected with the perforated steel plate connections.

\section{Composite beams}

\section{Observations and failure modes}

For the bamboo beam specimens of group B0, the fracture of bamboo fibers at the bottom in the mid-span region resulted in the failure of these beams. Taking B0-1 as an example, when the test load value reached the ultimate load $(57 \mathrm{kN})$, the bamboo fibers at the

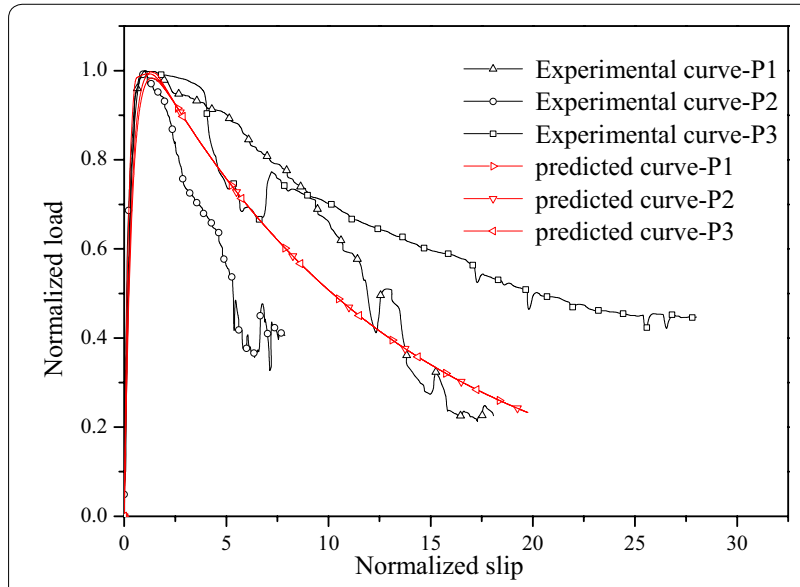

Fig. 10 Comparison of calculated and experimental load-slip curves of shear connectors bottom of the mid-span region were ruptured partially (Fig. 11a). The mid-span deflection of the specimen corresponding to the ultimate load was $58.7 \mathrm{~mm}$ (approximately $1 / 45$ of the span), and the deformation of the specimen was significantly large and obvious according to the appearance.

The failure modes of composite beams can be summarized as two types. The first type was the tensile fracture of bamboo fibers on the bottom of bamboo beams, with the concrete part not suffering significant damage; in the second type, the top surface of concrete first exhibited longitudinal cracks along the centerline of the connectors, then the connection between the bamboo and the concrete by the connectors failed gradually, and finally, the bamboo beam failed.

BP250-2 and BP300-1 belong to the first failure mode. Taking BP250-2 as an example, the concrete did not exhibit obvious damage during loading. When loading to $80 \mathrm{kN}$, the bamboo fiber at the middle and bottom of the bamboo beam suddenly ruptured in a large area, accompanied by a continuous cracking sound (Fig. 11b).

Groups BP100, BP150, and BP200, and specimens BP250-1 and BP300-2 belong to the second failure mode. When the specimens were loaded to $50-90 \%$ of the ultimate bearing capacity, longitudinal cracks along the centerline of the connectors appeared on the top surface of the concrete, and the load value continued to increase to the ultimate load after a small drop. Then, the bamboo fibers at the middle and bottom of the beam span ruptured in a large area, cracks developed toward both ends of the beams at both sides, resulting in a number of longitudinal cracks, and the bearing capacity decreased sharply (Fig. 11c, d). The split failure occurring at the center of the concrete can be attributed to the following reasons: the top cover concrete thickness of the steel plates is too small and the ratio of the transverse steel bars is relatively low, especially, the wide and dense connecting plate occupies too much cross-sectional area on the longitudinal shear surface of the connection, so that the cross-sectional area of the shear concrete is reduced too much. Additionally, the load of concrete cracking of specimens with the second failure mode was affected by the center spacing of the shear steel plates. For instance, the composite beams with a $100-\mathrm{mm}$ steel plate center spacing had the smallest spacing, but concrete cracks first occurred in BP100 specimens with the smallest load compared to other groups. When the BP100 specimens were loaded to approximately $50 \%$ of the ultimate bearing capacity, longitudinal cracks appeared on the concrete's top surface. This phenomenon should be attributed to the fact that overly small connector spacing makes the steel plates used in the composite beams connect closely to increase integrity, resulting in the shear area of concrete 


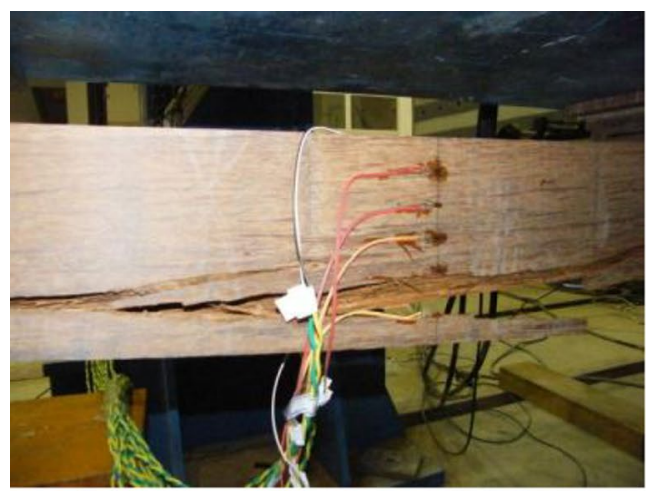

a Bamboo beam fracture (B0-1)

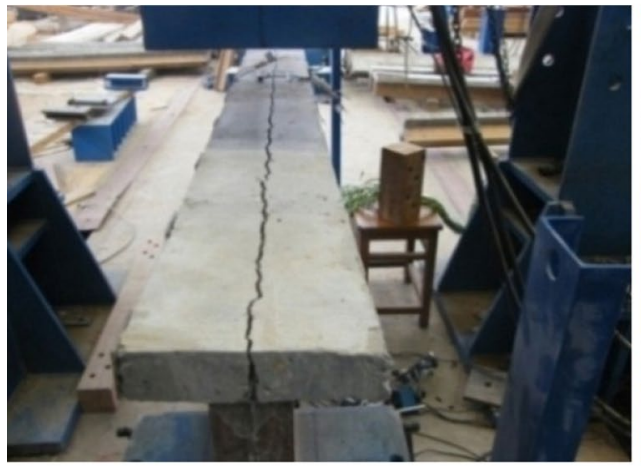

C Longitudinal cracks of concrete (BP300-2)

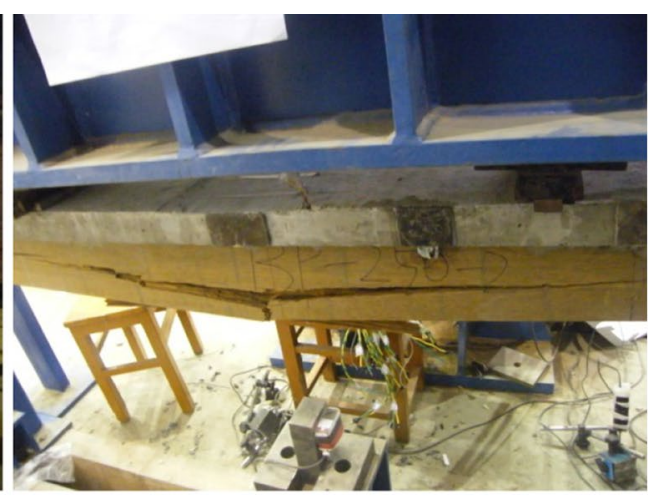

b Fracture of bamboo without concrete failure (BP250-2)

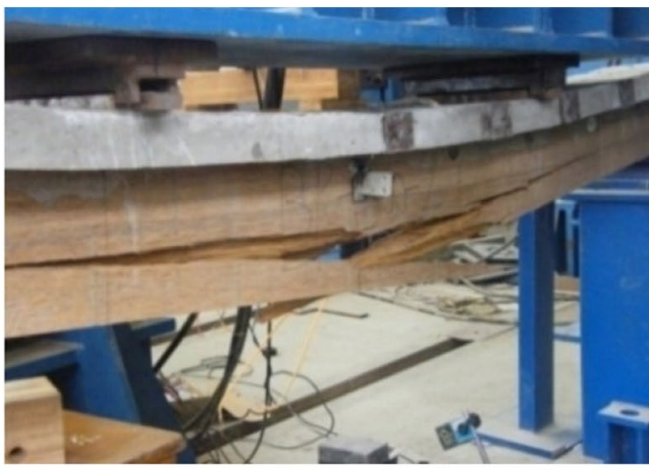

d Fracture of bamboo of composite beam (BP300-2)

Fig. 11 Failure models of beam specimens

and the longitudinal shear capacity of the concrete part being greatly decreased.

\section{Load-displacement curve}

The load-displacement curves of the specimens are shown in Fig. 12. The load-displacement curves of the benchmark bamboo beams showed an approximate linear relationship, and the average mid-span displacement was $59.0 \mathrm{~mm}$ (approximately $1 / 45$ of the span) when the beams failed. This indicates that the deformation of the bamboo beam at the ultimate state was too large, and the sectional stiffness of the bamboo flexural member was insufficient to bear the heavy load.

The load-displacement curves of the composite beams were basically similar. At less than $40 \%$ of the ultimate load, the load-displacement curves were also linear. Subsequently, the trend of nonlinearity became increasingly obvious, which may be attributed to the interface slip of composite beams, nonlinear behavior of concrete under compression and concrete cracking longitudinally on the concrete top surface, which leads to a reduction of section stiffness. Compared with bamboo beams, the ultimate load of bamboo-concrete composite beams increased by $1.2-1.5$ times. In particular, the composite beams with $100-\mathrm{mm}$ steel plate center spacing had the smallest spacing, but they failed first. The steel plate caused a great reduction in the longitudinal shear area of concrete. The entire sectional stiffness of group-BP150, group-BP200, group-BP250 and group-BP300 specimens decreased gradually with the increase of center spacing of the perforated steel plate. Compared with bamboo beams, the sectional stiffness of the composite beams was greatly improved, and the mid-span deflections of the composite beams under various loads were significantly reduced. At the later stage of loading, due to the cracking of the concrete and the fracture of the bamboo fibers, the effective section of composite beams is reduced, so that the actual stiffness of the composite beams may be lower than that of the two beams with no combination.

The test results of the specimens are shown in Table 3. The mid-span displacements of specimens subjected to load of $30 \mathrm{kN}$ were listed in the table. The mid-span displacements of bamboo beams and composite beams were averagely $27.45 \mathrm{~mm}$ and 6.3-9.5 mm, respectively. Compared with bamboo beams, the stiffness of composite beams increased by 


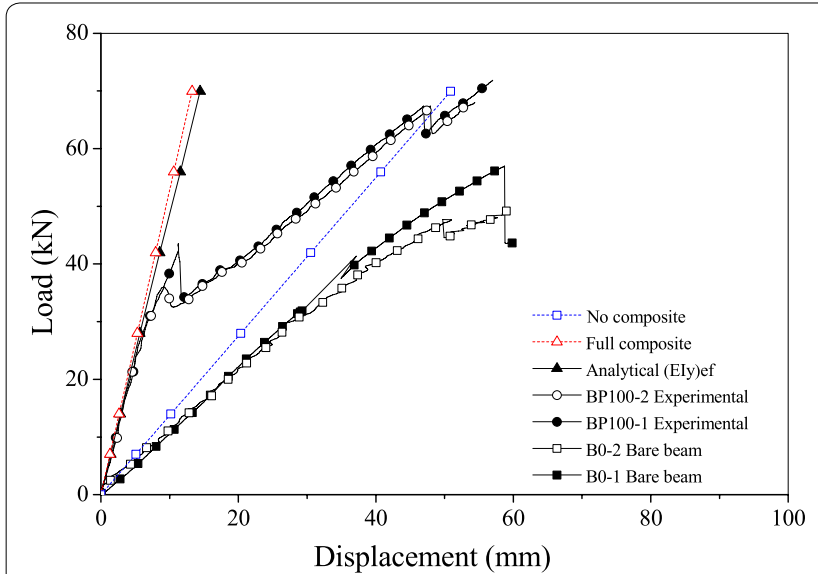

a Group BP100 (S=100 mm)

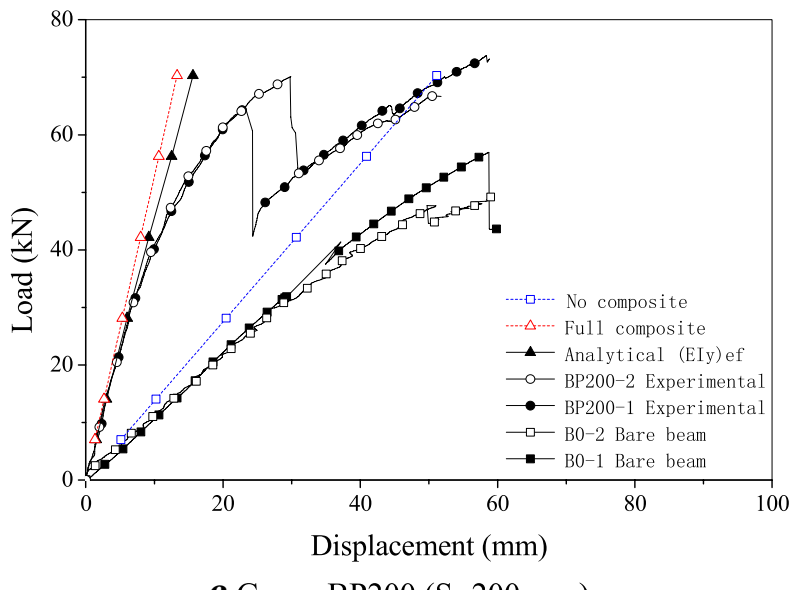

c Group BP200 (S=200 mm)
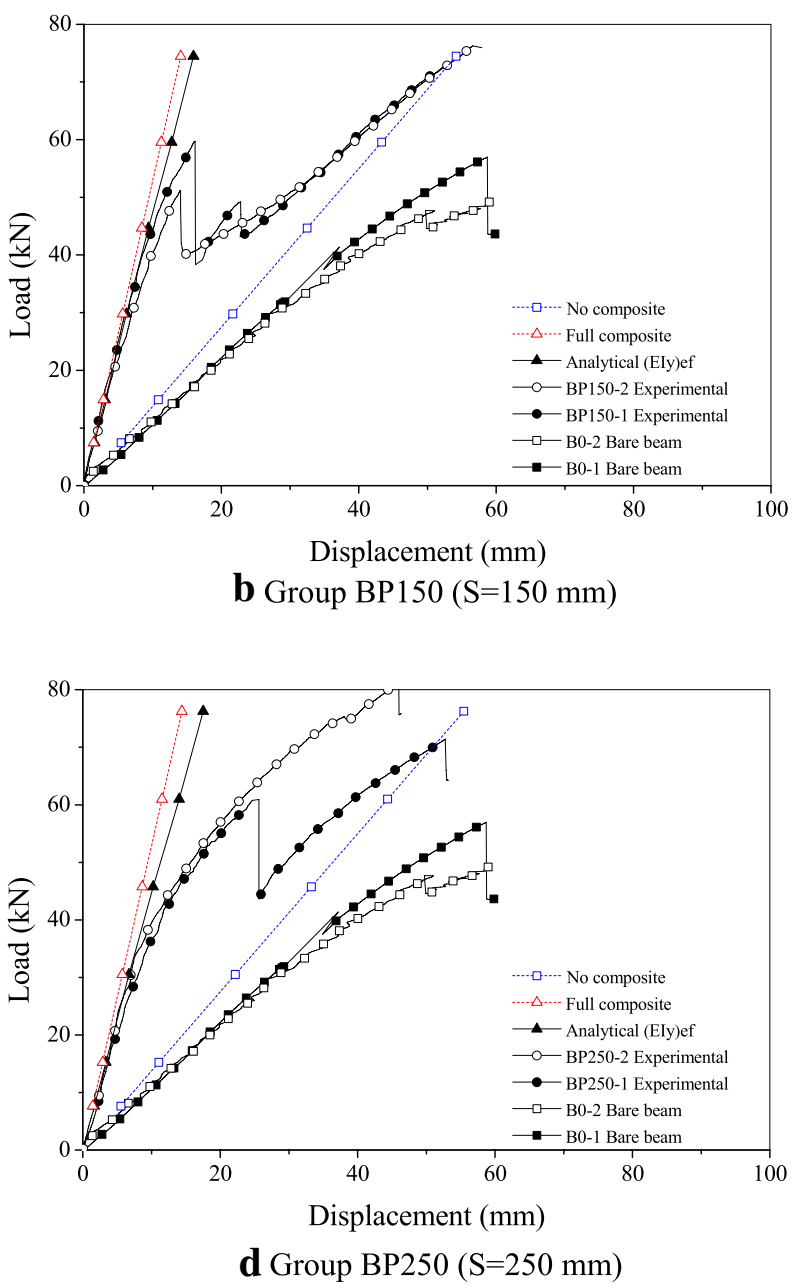

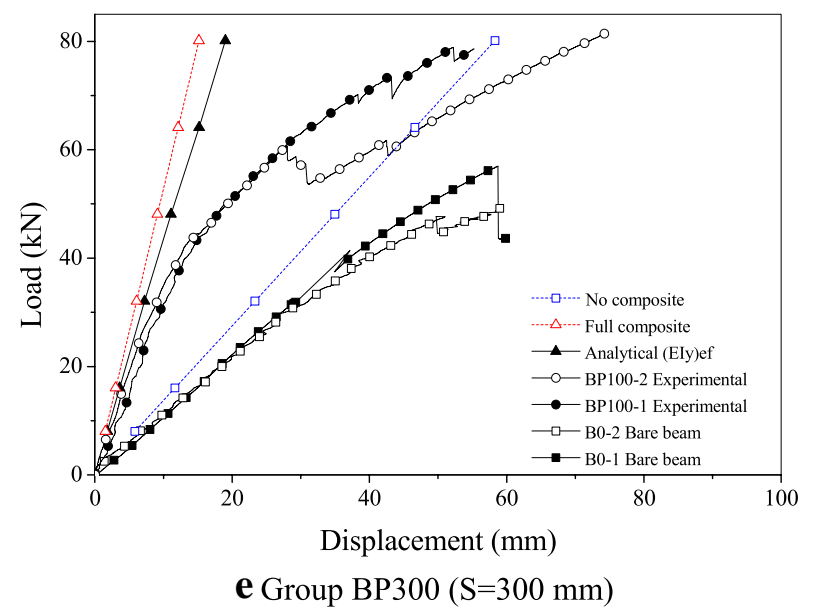

Fig. 12 Load-displacement curves of beam specimens

2.89-4.36 times. According to the Eurocode 5, when wood beams are employed as floor beams or slabs, the displacement limit corresponds to the serviceability limit state is prescribed as $L / 300$ ( $L$ is the span of the beams or slabs). The results indicated that the load $P_{L / 300}$ corresponds to the serviceability limit state of 
Table 3 Test results of specimens

\begin{tabular}{|c|c|c|c|c|c|c|c|c|c|c|c|c|c|c|}
\hline \multirow[t]{2}{*}{ Specimen } & \multicolumn{3}{|c|}{$P=30 \mathrm{kN}$} & \multicolumn{3}{|c|}{$\Delta=L / 300$} & \multicolumn{3}{|c|}{$\begin{array}{l}\text { Longitudinal } \\
\text { cracking state }\end{array}$} & \multicolumn{3}{|c|}{ Ultimate state } & \multirow[t]{2}{*}{$P_{L / 300} / P_{\max }$} & \multirow[t]{2}{*}{$P_{S_{\mathrm{u}}} / P_{\max }$} \\
\hline & $\Delta$ & $\begin{array}{l}\text { Stiffness } \\
\text { increase } \\
\text { times }\end{array}$ & $E$ & $P_{L / 300}$ & $\begin{array}{l}\text { Increase } \\
\text { times of } P_{L / 300}\end{array}$ & $E$ & $P_{s_{\mathrm{u}}}$ & $\boldsymbol{\Delta}_{s_{\mathrm{u}}}$ & $E$ & $P_{\max }$ & $\begin{array}{l}\text { Increase } \\
\text { times of } P_{\max }\end{array}$ & $\Delta_{\max }$ & & \\
\hline B0-1 & 27.2 & - & - & 8.4 & - & - & - & - & - & 57.0 & - & 58.7 & 0.15 & - \\
\hline BO-2 & 27.7 & - & - & 8.8 & - & - & - & - & - & 49.5 & - & 59.2 & 0.18 & - \\
\hline BP100-1 & 6.6 & 4.16 & 0.94 & 33.7 & 3.92 & 0.91 & 42.3 & 11.4 & 0.85 & 71.9 & 1.35 & 57.0 & 0.47 & 0.59 \\
\hline BP100-2 & 6.7 & 4.10 & 0.94 & 33.2 & 3.86 & 0.90 & 36.0 & 9.4 & 0.87 & 68.0 & 1.28 & 54.4 & 0.49 & 0.53 \\
\hline BP150-1 & 6.3 & 4.36 & 0.96 & 38.0 & 4.42 & 0.96 & 59.3 & 15.7 & 0.86 & 72.7 & 1.37 & 52.3 & 0.52 & 0.82 \\
\hline BP150-2 & 7.0 & 3.92 & 0.92 & 33.2 & 3.86 & 0.90 & 51.0 & 13.8 & 0.85 & 76.2 & 1.43 & 56.6 & 0.44 & 0.67 \\
\hline BP200-1 & 6.7 & 4.10 & 0.94 & 33.8 & 3.93 & 0.91 & 64.7 & 23.3 & 0.68 & 73.8 & 1.39 & 58.4 & 0.46 & 0.88 \\
\hline BP200-2 & 6.5 & 4.22 & 0.95 & 34.3 & 3.99 & 0.92 & 70.2 & 29.7 & 0.56 & 66.8 & 1.25 & 50.6 & 0.51 & 1.05 \\
\hline BP250-1 & 8.0 & 3.43 & 0.86 & 30.3 & 3.52 & 0.86 & 61.1 & 25.6 & 0.57 & 71.4 & 1.34 & 52.7 & 0.42 & 0.86 \\
\hline BP250-2 & 6.9 & 3.98 & 0.92 & 34.7 & 4.03 & 0.92 & - & - & - & 81.1 & 1.52 & 45.8 & 0.43 & - \\
\hline BP300-1 & 9.5 & 2.89 & 0.76 & 26.8 & 3.12 & 0.80 & - & - & - & 78.6 & 1.48 & 55.3 & 0.34 & - \\
\hline ВР300-2 & 8.4 & 3.27 & 0.83 & 29.2 & 3.40 & 0.84 & 60.7 & 28 & 0.49 & 81.7 & 1.53 & 74.7 & 0.36 & 0.74 \\
\hline
\end{tabular}

$P$ is the load, $\mathrm{kN}$; $\Delta$ is the mid-span displacement, $\mathrm{mm}$; the results of bamboo beams are referred to evaluate the increase times of composite beams

the composite beams increases by 3.12-4.42 times compared with the bamboo beams at the mid-span displacement of the $L / 300$. In addition, the values of $P_{L / 300} / P_{\max }$ for bamboo beams and composite beams were $0.15-0.18$ and $0.39-0.60$, respectively, which indicated that the bearing capacity of composite beams can be utilized with a higher efficiency under service state. Combination efficiency coefficient $E$ can be used to describe the degree of combination of composite structures [33]. $E=1$ means complete combination, and $E=0$ means non-composite structures. A greater $E$ value indicates a higher degree of combination of structures with a greater stiffness and bearing capacity:

$$
E=\frac{\Delta_{\mathrm{NC}}-\Delta_{\mathrm{PC}}}{\Delta_{\mathrm{NC}}-\Delta_{\mathrm{FC}}},
$$

where $\Delta$ is mid-span displacement; subscripts NC, FC and $\mathrm{PC}$ represent no combination, complete combination and partial combination, respectively.

The combined efficiency coefficients under different load levels are given in the table. When $P=30 \mathrm{kN}$, $E=0.76-0.96$; when $\Delta=L / 300, E=0.80-0.96$. With a smaller center spacing of steel plate, a larger $E$ value can be obtained. The results show that the mechanical properties of composite beams are between complete combinations and partial combinations. With a smaller center spacing of steel plate, a greater stiffness and a higher the combination efficiency can be achieved for the composite beams.

\section{Analysis of section stress and interface slip}

Figure 13 shows the strain distribution of each specimen in the mid-span section. Bamboo beam specimens were subjected to upper compression and lower tension, and the neutral axis was approximately $1 / 2$ of the height of the section. During the loading process, the position of the neutral axis hardly changed. For composite beams, at the initial stage of loading, the strain of the concrete cross-section of the composite beams was under full compression, the upper part of bamboo was under compression, and the lower part was under tension. For small strain range (such as the load is below $20 \mathrm{kN})$, the neutral axis point is almost unchanged. When the concrete cracked, the perforated steel plate connectors began to fail gradually, and the strain of the concrete section changed from full compression to upper compression and lower tension. There was a strain difference between the upper and lower interfaces, which exhibited the characteristics of slip at the composite interface. The deformation of concrete and bamboo no longer conforms to the principle of flat section, and the neutral axis point is changed with the development of stress state of concrete and bamboo, respectively. Correspondingly, the depth of compression of bamboo increased gradually, and the depth of tension decreased. In contrast, the maximum tensile strains of bamboo in the composite beams were close to those of bamboo in the bamboo beam specimens at the ultimate state, which indicates that the strength of bamboo was fully utilized, corresponding to the 


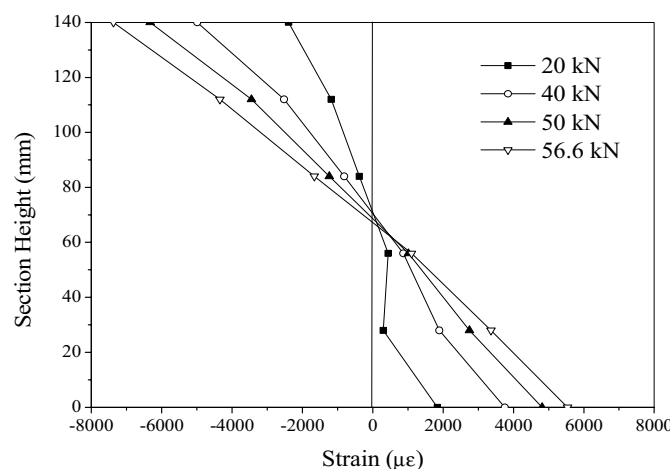

a $\mathrm{B} 0-1$

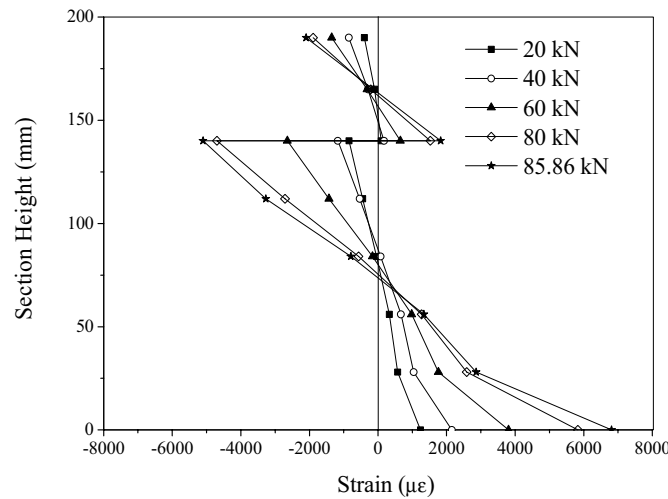

c BP100-1

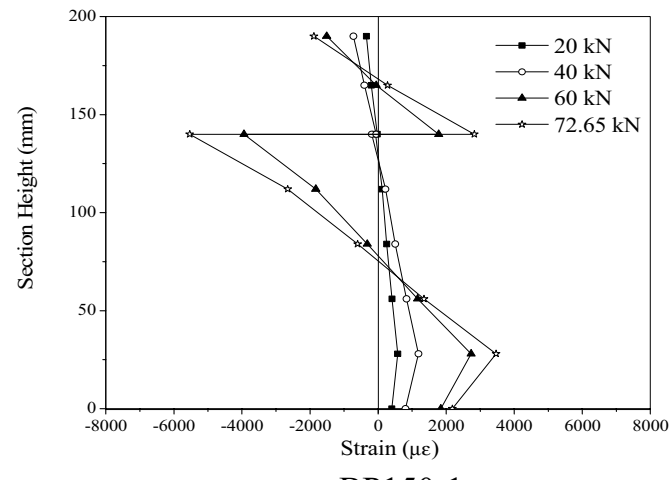

e BP150-1

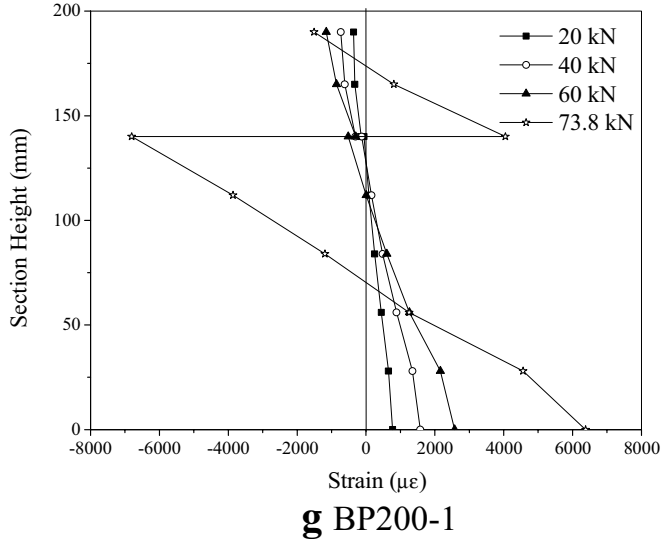

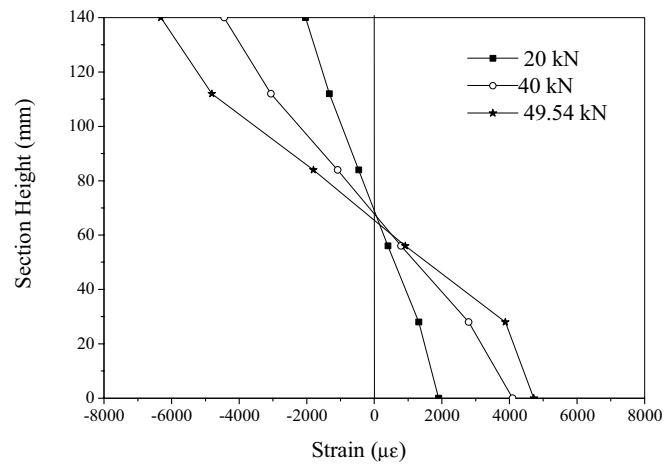

b $\mathrm{B} 0-2$

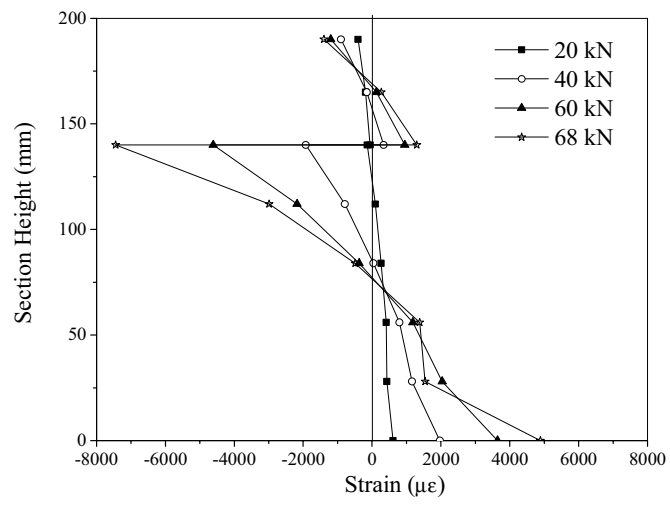

d BP100-2

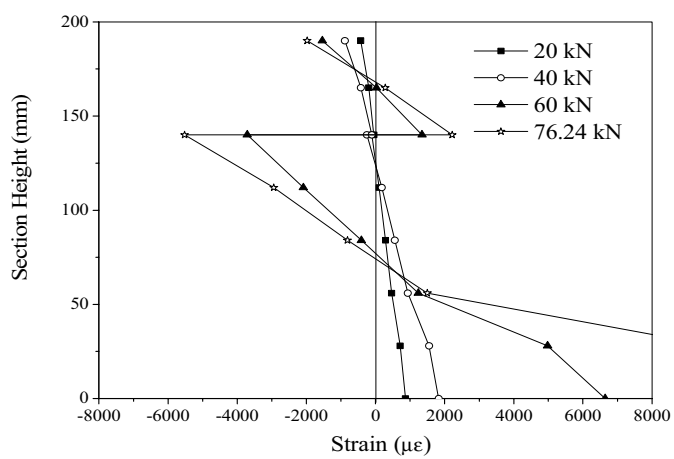

f $\mathrm{BP} 150-2$

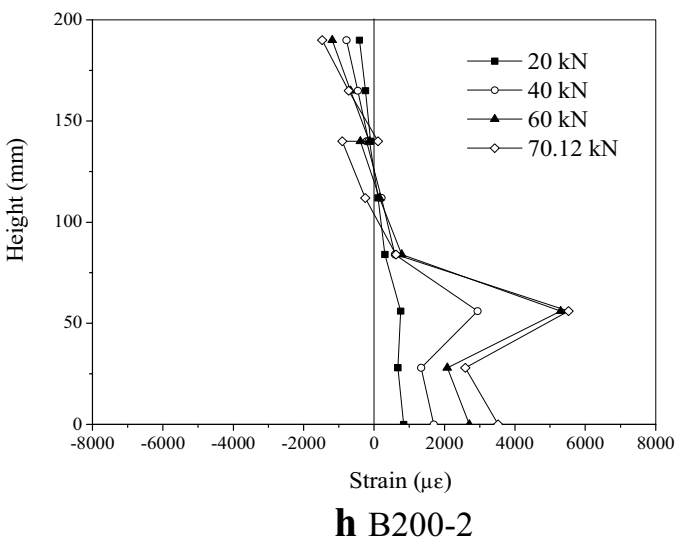

Fig. 13 Strain distributions at the mid-span cross section of beam specimens 


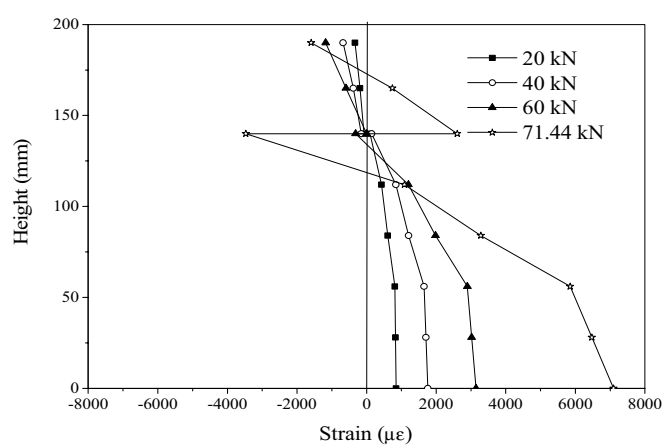

i $\mathrm{BP} 250-1$

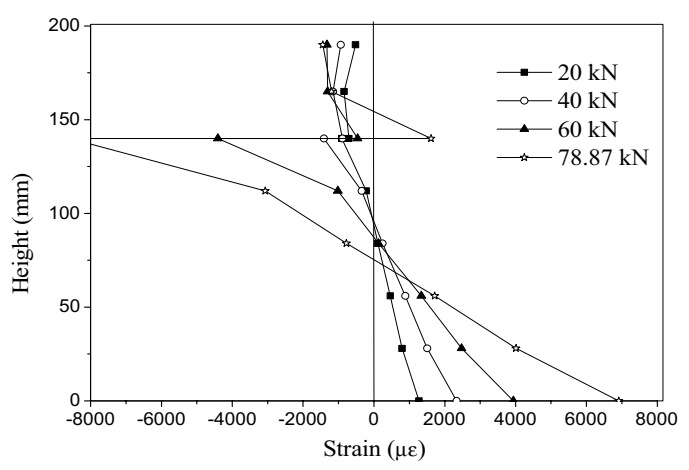

k BP300-1

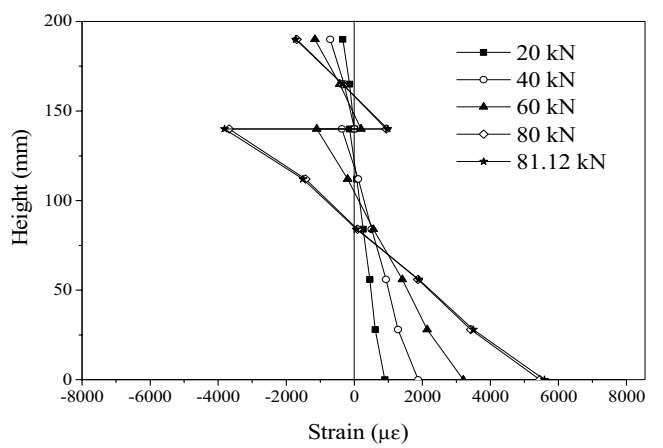

j $\mathrm{BP} 250-2$

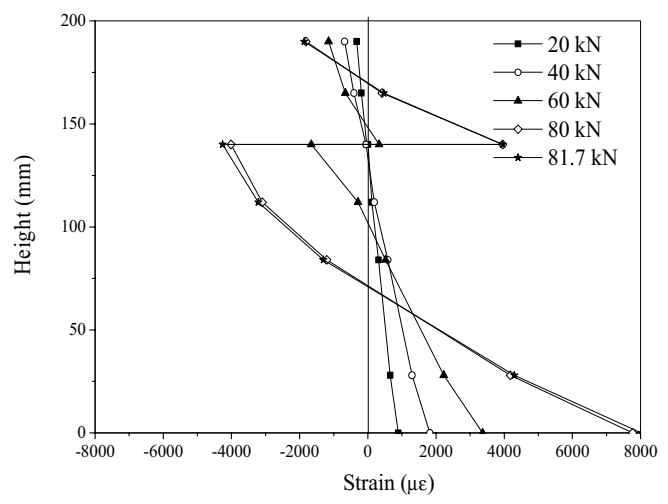

I BP300-2

Fig. 13 continued

ultimate load if the connectors can work well until the ultimate load. Alternately, the maximum compressive strains of concrete in the composite beams were smaller than $2000 \mu \varepsilon$ in general, and it was difficult to make full use of the concrete strength due to the fracture of bamboo or the pre-failure of the connectors.

Figure 14 shows the measured load-slip curves at the interface of composite beams from the mid-span position to the support position. It can be seen that the interface slip of each composite beam was very small (almost no slip) at the initial stage of loading. For the first type of failure specimens, when the load reached approximately $30 \mathrm{kN}$ (approximately $40 \%$ of the ultimate load), the slip increased gradually with the increase of the load, and the slip steadily increased. For the second type of failure specimens, the slip also increased steadily with the increase of the load until the concrete cracks occurred on the top surface of the composite beam, and there was a sharp increase in slip value corresponding to the sudden failure of connectors. Then, the load value may continue to increase after a short drop, and the interface slip can continue to increase steadily. The connectors failed gradually as the slip increased. Table 4 shows the relative slip values at the interface of composite beams under different load levels. The relative slip value corresponding to $P_{L / 300}$ ranged between 0.11 and $0.23 \mathrm{~mm}$. $P_{L / 300}$ is the corresponding load when the mid-span displacement is $L / 300$. The relative slip value corresponding to $P_{L / 250}$ ranged between 0.17 and $0.41 \mathrm{~mm}$. It can be seen that the relative slip increased with the increase of mid-span displacement. When the load-displacement curve of composite beams was linear in the early loading stages, the relative slip value decreased with the decrease of the spacing of steel plates. In the later stage of loading, the failure of the connectors caused the slip to increase sharply, and there was no good correspondence between the value of the slip and the spacing of the connectors. The value of the interface slip increased from mid-span to the end of the beams, and the slip developed stably in the early stage. In the later stage, the interface slip increased sharply when the load increased slowly, and the load-slip curve developed unsteadily. 


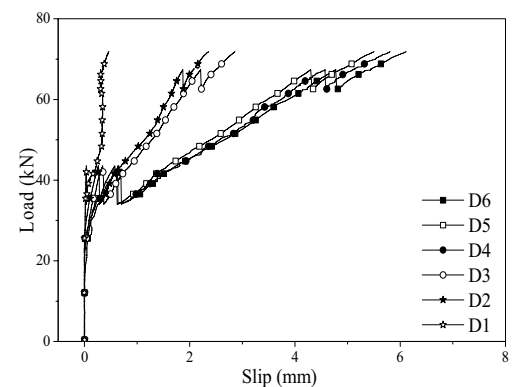

a BP100-1

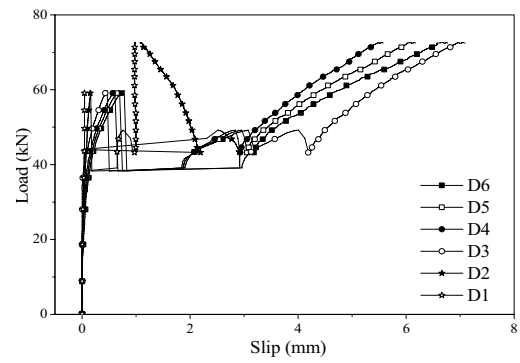

c BP150-1

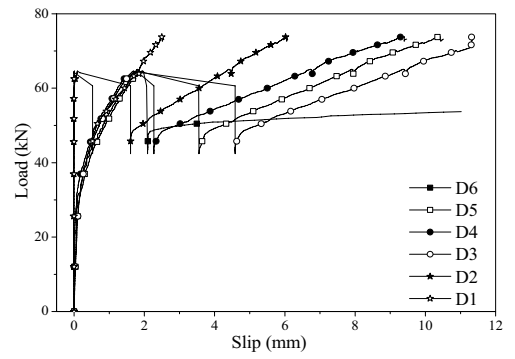

e BP200-1

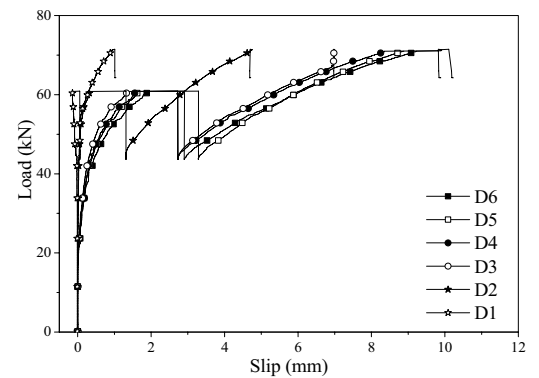

g BP250-1

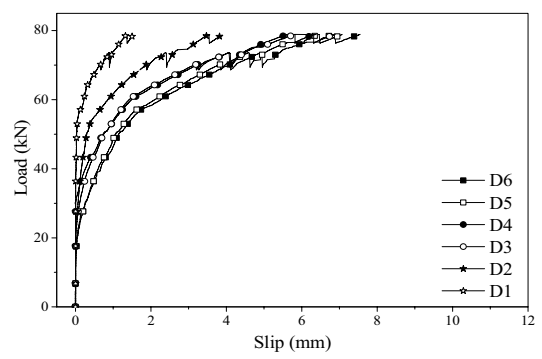

i BP300-1

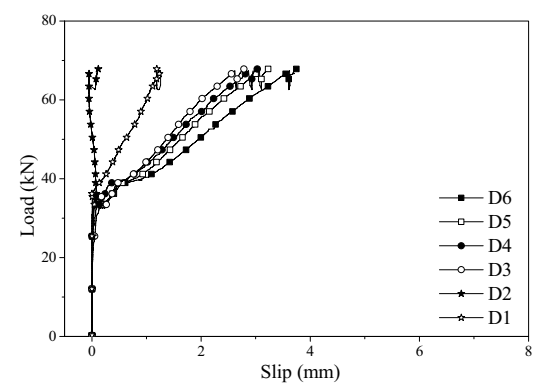

b BP100-2

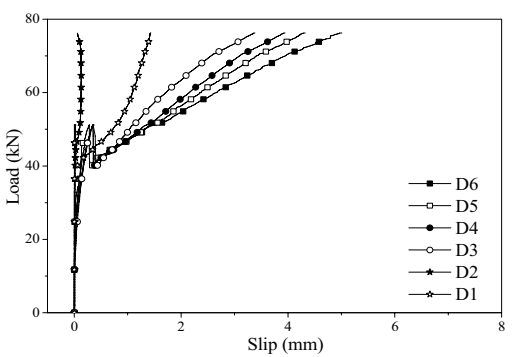

d BP150-2
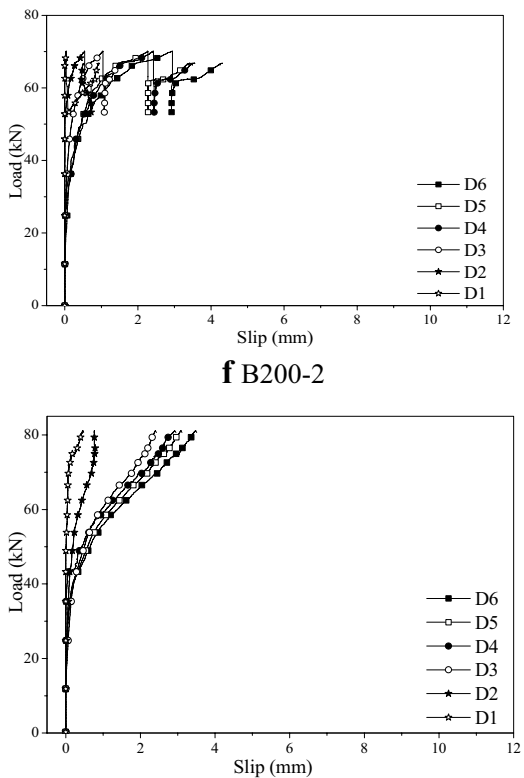

h $\mathrm{BP} 250-2$

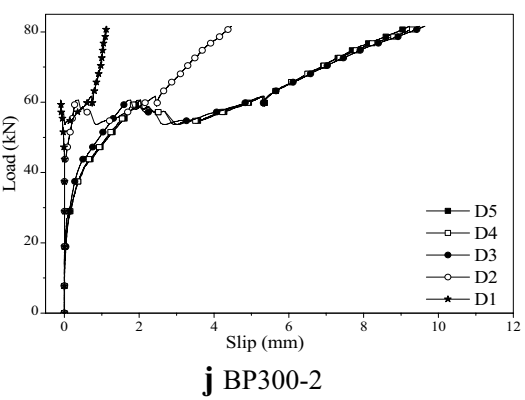

Fig. 14 Load-slip curves of bamboo-concrete composite beam specimens 
Table 4 Maximum slip under different load levels

\begin{tabular}{|c|c|c|c|c|c|c|c|c|}
\hline Specimens & Load (kN) & Slip (mm) & $P_{L / 300}(\mathrm{kN})$ & Slip (mm) & $P_{L / 250}(\mathrm{kN})$ & Slip (mm) & $\begin{array}{l}\text { Ultimate load } \\
(\mathrm{kN})\end{array}$ & Slip (mm) \\
\hline BP100-1 & 30 & 0.12 & 33.7 & 0.23 & 37.4 & 0.41 & 71.9 & 6.12 \\
\hline BP100-2 & 30 & 0.08 & 33.2 & 0.14 & 35.5 & 0.17 & 68.0 & 3.76 \\
\hline BP150-1 & 30 & 0.04 & 38.0 & 0.14 & 43.3 & 0.21 & 72.7 & 6.97 \\
\hline BP150-2 & 30 & 0.09 & 33.2 & 0.11 & 39.5 & 0.17 & 76.2 & 5.01 \\
\hline BP200-1 & 30 & 0.15 & 33.8 & 0.24 & 39.2 & 0.40 & 73.8 & 13.35 \\
\hline BP200-2 & 30 & 0.09 & 34.3 & 0.14 & 39.8 & 0.24 & 66.8 & 4.31 \\
\hline BP250-1 & 30 & 0.12 & 30.3 & 0.12 & 35.6 & 0.21 & 71.4 & 10.11 \\
\hline BP250-2 & 30 & 0.06 & 34.7 & 0.14 & 38.5 & 0.19 & 81.1 & 3.49 \\
\hline ВР300-1 & 30 & 0.27 & 26.8 & 0.17 & 30.6 & 0.29 & 78.6 & 7.49 \\
\hline ВР300-2 & 30 & 0.20 & 29.2 & 0.16 & 33.9 & 0.28 & 81.7 & 9.64 \\
\hline
\end{tabular}

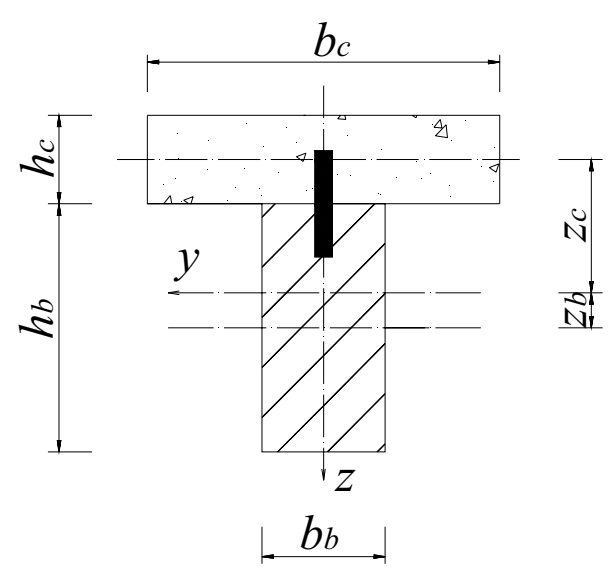

Fig. 15 Cross-section of bamboo-concrete composite beam

\section{Theoretical analysis}

According to the test results and referring to Eurocode 5, for a composite structure composed of two parts through shear connectors (Fig. 15), the section stiffness can be calculated via the equivalent section stiffness $\left(\mathrm{EI}_{\mathrm{y}}\right)_{\mathrm{ef}}$ (Formula (6)). The connection coefficient $\gamma_{\mathrm{b}}$ (Formulas (7) and (8)) is used to describe the reduction of stiffness due to interface slip. $\gamma_{\mathrm{b}}$ ranges between 0 and 1. $\gamma_{\mathrm{b}}=0$ means that there is no connection at the material interface of the composite structure, and $\gamma_{\mathrm{b}}=1.0$ means that the material interface is a rigid connection. The increase of the value of $\gamma_{b}$ indicates that the slip stiffness of the connector increases. The relevant Formulas are given as follows:

$$
\begin{aligned}
\left(E I_{\mathrm{y}}\right)_{\mathrm{ef}}= & E_{\mathrm{c}}\left(\frac{h_{\mathrm{c}}^{3} \cdot b_{\mathrm{c}}}{12}+\gamma_{\mathrm{b}} \cdot A_{\mathrm{c}} \cdot Z_{\mathrm{c}}^{2}\right) \\
& +E_{\mathrm{b}}\left(\frac{h_{\mathrm{b}}^{3} \cdot b_{\mathrm{b}}}{12}+A_{\mathrm{b}} \cdot Z_{\mathrm{b}}^{2}\right),
\end{aligned}
$$

where $\gamma_{\mathrm{b}}$ is the connection coefficient, calculated according to Formulas (7) and (8). $E_{\mathrm{c}}$ is the elastic modulus of concrete, $\mathrm{N} / \mathrm{mm}^{2} ; E_{\mathrm{b}}$ is the elastic modulus of bamboo, $\mathrm{N} / \mathrm{mm}^{2} ; n_{\mathrm{c}}$ is the section conversion coefficient between concrete and bamboo, $n_{\mathrm{c}}=E_{\mathrm{c}} / E_{\mathrm{b}} ; A_{\mathrm{c}}$ is the section area of concrete, $\mathrm{mm}^{2} ; A_{\mathrm{b}}$ is the section area of bamboo, $\mathrm{mm}^{2}$; $h_{\mathrm{b}}$ is the height of the bamboo beam, $\mathrm{mm} ; h_{\mathrm{c}}$ is the height of the concrete flange, $\mathrm{mm} ; Z_{\mathrm{b}}$ is the distance from the center of the bamboo beam to the neutral axis, $\mathrm{mm} ; Z_{\mathrm{c}}$ is the distance from the center of the concrete to the neutral axis, $\mathrm{mm} ; b_{\mathrm{b}}$ is the width of the bamboo beam; and $b_{\mathrm{c}}$ is the width of the concrete flange, $\mathrm{mm}$.

$$
\begin{aligned}
& \gamma_{\mathrm{b}}=\frac{1}{1+k}, \\
& k=\frac{\pi^{2} \cdot E_{\mathrm{c}} \cdot A_{\mathrm{c}} \cdot s_{\mathrm{i}}}{K \cdot l^{2}},
\end{aligned}
$$

where $s_{\mathrm{i}}$ is the effective spacing of shear connectors, $\mathrm{mm}$; $K$ is the shear slip stiffness of shear connectors, $\mathrm{N} / \mathrm{mm}$; $l$ is the span of beams, $\mathrm{mm} ; E_{\mathrm{c}}$ is the elastic modulus of concrete, $\mathrm{N} / \mathrm{mm}^{2} ; A_{\mathrm{c}}$ is the cross-sectional area of concrete, $\mathrm{mm}^{2} ; k$ is a dimensionless quantity that reflects the combined influence of the slip stiffness and spacing of connectors, concrete cross-sectional area and material properties on the connection coefficient.

In Formula (6), $Z_{\mathrm{b}}$ and $Z_{\mathrm{c}}$ are calculated by Formula (9) and Formula (10), respectively.

$$
\begin{aligned}
& Z_{\mathrm{b}}=\frac{n_{\mathrm{c}} \gamma_{\mathrm{b}} A_{\mathrm{c}}\left(h_{\mathrm{b}}+h_{\mathrm{c}}\right)}{2\left(n_{\mathrm{c}} \gamma_{\mathrm{b}} A_{\mathrm{c}}+A_{\mathrm{b}}\right)}, \\
& Z_{\mathrm{c}}=\frac{h_{\mathrm{b}}+h_{\mathrm{c}}}{2}-Z_{\mathrm{b}} .
\end{aligned}
$$

Ignoring the influence of shear force and axial force, the formula for calculating mid-span displacement of 
Table 5 Results of numerical analysis of the bamboo-concrete composite beams

\begin{tabular}{|c|c|c|c|c|c|c|}
\hline Specimens & Parameters & $\begin{array}{l}\text { Serviceability limit } \\
\text { state }\end{array}$ & Ultimate limit state & Critical failure & Unit & Formula \\
\hline & K & 196.675 & 171.45 & 145.25 & $\mathrm{kN} / \mathrm{mm}$ & (1) \\
\hline \multirow[t]{4}{*}{ BP100 } & $\gamma_{\mathrm{b}}$ & 0.80 & 0.78 & 0.75 & - & $(7)$ \\
\hline & $z_{\mathrm{b}}$ & 54.19 & 53.52 & 52.61 & $\mathrm{~mm}$ & (9) \\
\hline & $Z_{c}$ & 40.81 & 41.48 & 42.38 & $\mathrm{~mm}$ & $(10)$ \\
\hline & $\left(\left.E\right|_{y}\right)_{\text {ef }}$ & $1.22 \times 10^{9}$ & $1.20 \times 10^{9}$ & $1.19 \times 10^{9}$ & $\mathrm{kN} \mathrm{mm^{2 }}$ & (6) \\
\hline \multirow[t]{4}{*}{ BP150 } & $\gamma_{\mathrm{b}}$ & 0.73 & 0.70 & 0.67 & - & $(7)$ \\
\hline & $z_{\mathrm{b}}$ & 51.99 & 51.07 & 49.84 & $\mathrm{~mm}$ & (9) \\
\hline & $Z_{c}$ & 43.01 & 43.93 & 45.16 & $\mathrm{~mm}$ & (10) \\
\hline & $\left(\left.E\right|_{y}\right)_{e f}$ & $1.18 \times 10^{9}$ & $1.16 \times 10^{9}$ & $1.14 \times 10^{9}$ & $\mathrm{kN} \mathrm{mm^{2 }}$ & (6) \\
\hline \multirow[t]{4}{*}{ BP200 } & $\gamma_{\mathrm{b}}$ & 0.67 & 0.64 & 0.60 & - & $(7)$ \\
\hline & $z_{\mathrm{b}}$ & 49.96 & 48.84 & 47.34 & $\mathrm{~mm}$ & (9) \\
\hline & $Z_{c}$ & 45.04 & 46.16 & 47.66 & $\mathrm{~mm}$ & $(10)$ \\
\hline & $\left(\left.E\right|_{y}\right)_{\text {ef }}$ & $1.15 \times 10^{9}$ & $1.13 \times 10^{9}$ & $1.10 \times 10^{9}$ & $\mathrm{kN} \mathrm{mm^{2 }}$ & (6) \\
\hline \multirow[t]{4}{*}{ BP250 } & $\gamma_{\mathrm{b}}$ & 0.62 & 0.59 & 0.55 & - & $(7)$ \\
\hline & $z_{b}$ & 48.08 & 46.79 & 45.09 & $\mathrm{~mm}$ & (9) \\
\hline & $Z_{c}$ & 46.92 & 48.21 & 49.91 & $\mathrm{~mm}$ & $(10)$ \\
\hline & $\left(E I_{y}\right)_{e f}$ & $1.12 \times 10^{9}$ & $1.10 \times 10^{9}$ & $1.07 \times 10^{9}$ & $\mathrm{kN} \mathrm{mm^{2 }}$ & (6) \\
\hline \multirow[t]{4}{*}{ BP300 } & $\gamma_{\mathrm{b}}$ & 0.58 & 0.54 & 0.50 & - & (7) \\
\hline & $z_{b}$ & 46.34 & 44.91 & 43.03 & $\mathrm{~mm}$ & (9) \\
\hline & $Z_{c}$ & 48.66 & 50.09 & 51.97 & $\mathrm{~mm}$ & (10) \\
\hline & $\left(E I_{y}\right)_{\mathrm{ef}}$ & $1.09 \times 10^{9}$ & $1.06 \times 10^{9}$ & $1.03 \times 10^{9}$ & $\mathrm{kN} \mathrm{mm^{2 }}$ & (6) \\
\hline
\end{tabular}

bending specimens under four-point loading can be obtained in this paper:

$$
\Delta=\frac{P a}{48\left(\mathrm{EI}_{\mathrm{y}}\right)_{\mathrm{ef}}}\left(3 l^{2}-4 a^{2}\right),
$$

where $\Delta$ is the mid-span displacement of the specimen, $\mathrm{mm} ; P$ is the total load of two loading points, $\left(\mathrm{EI}_{\mathrm{y}}\right)_{\mathrm{ef}}$ is the equivalent section stiffness, $\mathrm{N} \mathrm{mm}^{2} ; l$ is the span of the beam, mm; and $a$ is the distance between the loading point and the support, $\mathrm{mm}$.

The experimental bamboo-concrete composite beams are calculated according to Formulas (6)-(11), and the results are compared in Fig. 12. When $\gamma_{b}=0$, the calculation result shows that composite beams have no combination. When $\gamma_{\mathrm{b}}=1.0$, the calculation result shows that composite beams have a complete rigid connection. It can be seen that the test curve is between the complete combination curve and the noncombination curve. The values of $K_{\mathrm{s}, 0.4}, K_{\mathrm{s}, 0.6}$ and $K_{\mathrm{s}, 0.8}$ in Table 2 are substituted into Formulas (7)-(10), respectively, and $\gamma_{\mathrm{b}}$ is obtained. The equivalent section stiffness $\left(\mathrm{EI}_{\mathrm{y}}\right)_{\mathrm{ef}}$ is calculated by substituting $\gamma_{\mathrm{b}}$ into Formula (6), and the mid-span displacement under different loads is calculated by substituting $\left(\mathrm{EI}_{\mathrm{y}}\right)_{\text {ef }}$ into Formula (11). The calculation results are shown in Table 5 . The calculation results show that the effect of slip stiffness on the equivalent stiffness of cross section is not sensitive, and a $35 \%$ increase in slip stiffness results in a maximum increase in equivalent section stiffness of only $6 \%$ (BP300). The connection coefficient $\gamma_{\mathrm{b}}$ ranges between 0.50 and 0.80 and decreases as the center spacing of the perforated steel plate increases. For the loaddisplacement calculation curves of composite beams, the initial stage is in good agreement with the experimental curves until the elastic limit. In the nonlinear hardening stage, the errors between the calculated and experimental values are large due to nonlinear behavior of concrete under compression and concrete cracking longitudinally on the concrete's top surface. It should be noted that the calculation curve in Fig. 12, and the equivalent cross-section stiffness obtained by different load stages of the shear slip stiffness were calculated; in fact, the calculated curve is a line with three segments, but it looks like a straight line. It can be seen that a slight change of slip stiffness has no significant effect on the equivalent section stiffness.

\section{Conclusions}

This study presents a new type of bamboo-concrete composite beam with perforated steel plate connections. An experimental program was conducted to investigate 
the mechanical behavior of the composite structures. The failure modes, the load-displacement relationship, the load carrying capability, the slip stiffness and the strain distribution of the composite structures were investigated. The following conclusions can be drawn:

1. For bamboo-concrete shear connectors with a perforated steel plate, failure occurs between the perforated steel plate and concrete, and there is no obvious damage between the perforated steel plate and bamboo. The specimens can withstand a high load and suffer a large plastic deformation, so the failure mode is moderate failure.

2. The load-slip curve of bamboo-concrete shear connectors can be divided into three stages: the elastic stage, elastic-plastic stage and descending stage. The load carrying capacity of perforated steel plate connectors is relatively stable and has excellent slip deformation capacity. Considering the three stages of the load-slip curve, an exponential function is proposed to describe the load-slip curve, and the calculated load-slip curves are in good agreement with the experimental curves.

3. The failure modes of composite beams can be summarized as two types. In the first type, the bamboo beam ruptures on the bottom and the concrete dose not suffer significant damage; in the second type, the top surface of the concrete first exhibits longitudinal cracks, and finally, the bamboo beam ruptures. The load of concrete cracking of specimens with the second failure mode was affected by the center spacing of shear steel plates. The second failure mode has not been recorded in relevant literature. It can be concluded that adding transversely distributed reinforcement for bamboo-concrete shear connectors with perforated steel plates should be considered, and the influence of the shear area of concrete must be evaluated.

4. Compared with bamboo beams, the ultimate load of the composite beams increases by 1.2-1.5 times, the sectional stiffness of composite beams is increased by 2.9-4.2 times, and the mid-span deflections of composite beams under various loads are significantly reduced. The stiffness of composite beam specimens decreases gradually with the increase of the center spacing of perforated steel plates.

5. Referring to the relevant specifications, the equivalent section stiffness is obtained after determining the connection coefficient. The connection coefficient $\gamma_{\mathrm{b}}$ ranges between 0.50 and 0.80 and decreases as the center spacing of the perforated steel plate increases. For the load-displacement calculation curves of composite beams, the initial stage is in good agree- ment with the experimental curves until the elastic limit. In the nonlinear hardening stage, the errors between the calculated and experimental values are large due to the nonlinear behavior of concrete under compression and concrete cracking longitudinally on the concrete's top surface. The equivalent cross-section stiffness obtained by different load stages of the shear slip stiffness is calculated to predict the midspan displacement. The calculation results show that the effect of slip stiffness on the equivalent stiffness of cross section is not sensitive, and a $35 \%$ increase in slip stiffness results in a maximum increase in equivalent section stiffness of only $6 \%$.

\section{Abbreviations}

LVDT: linear variable displacement transducer; DIC: digital image correlation.

\section{Acknowledgements}

The authors would like to acknowledge the financial support from the National Natural Science Foundation of China (No. 51208262 and No. 51778300), the Natural Science Foundation of Jiangsu Province (No. BK20191390), the "333 Project" (No. BRA2016421) and the "Qinglan Project" of Jiangsu Province (QL2017), as well as the Project of the Priority Academic Program Development of the Jiangsu Higher Education Institutions (PAPD).

\section{Authors' contributions}

ZW contributed to analysis of the data and discussion of the obtained results and was a major contributor in writing the manuscript. YW contributed to the design of this analysis study. NL contributed to examination of all of the tests. KZ contributed to examination of all of the tests. MD contributed to the verification of data. All authors read and approved the final manuscript.

\section{Funding \\ No funding.}

Availability of data and materials

Not applicable.

\section{Competing interests}

The authors declare that they have no competing interests.

\section{Author details}

1 School of Civil Engineering, Nanjing Forestry University, Nanjing 210037, People's Republic of China. ${ }^{2}$ School of Management Science and Engineering, Anhui University of Finance and Economics, Bengbu, People's Republic of China.

Received: 3 October 2019 Accepted: 16 January 2020

Published online: 28 January 2020

\section{References}

1. Chen G, Li HT, Zhou T, Li CL, Song YQ, Xu R (2015) Experimental evaluation on mechanical performance of OSB webbed parallel strand bamboo I-joist with holes in the web. Constr Build Mater 101(12):91-98. https:// doi.org/10.1016/j.conbuildmat.2015.10.041

2. Chen G, He B (2017) Stress-strain constitutive relation of OSB under axial loading: an experimental investigation. Bioresources 12(3):6142-6156. https://doi.org/10.15376/biores.12.3.6142-6156

3. Lee PH, Odlin M, Yin H (2014) Development of a hollow cylinder test for the elastic modulus distribution and the ultimate strength of bamboo. 
Constr Build Mater 51(2):235-243. https://doi.org/10.1016/j.conbuildma t.2013.10.051

4. Moran R, Webb K, Harries K, García JJ (2017) Edge bearing tests to assess the influence of radial gradation on the transverse behavior of bamboo. Constr Build Mater 131(1):574-584. https://doi.org/10.1016/j.conbuildma t.2016.11.106

5. Taufani AR, Nugroho ASB (2014) Proposed bamboo school buildings for elementary schools in Indonesia. Procedia Eng 95:5-14. https://doi. org/10.1016/j.proeng.2014.12.159

6. Tian LM, Kou YF, Hao JP (2019) Flexural behavior of sprayed lightweight composite mortar-original bamboo composite beams: experimental study. Bioresources 14(1):500-517. https://doi.org/10.15376/biore S.14.1.500-517

7. Moroz JG, Lissel SL, Hagel MD (2014) Performance of bamboo reinforced concrete masonry shear walls. Constr Build Mater 61(6):125-137. https:// doi.org/10.1016/j.conbuildmat.2014.02.006

8. Javadian A, Wielopolski M, Smith IFC, Hebel DE (2016) Bond-behavior study of newly developed bamboo-composite reinforcement in concrete. Constr Build Mater 122(9):110-117. https://doi.org/10.1016/j.conbu ildmat.2016.06.084

9. Karthik S, Rao PRM, Awoyera PO (2017) Strength properties of bamboo and steel reinforced concrete containing manufactured sand and mineral admixtures. J King Saud Univ Eng Sci 29(4):400-406. https://doi. org/10.1016/j.jksues.2016.12.003

10. Shangguan $W$, Zhong $Y$, Xing $X, Z$ hao $R$, Ren $H$ (2015) Strength models of bamboo scrimber for compressive properties. J Wood Sci 61 (2):1-8. https ://doi.org/10.1007/s10086-014-1444-9

11. Zhong Y, Wu G, Ren H, Jiang Z (2017) Bending properties evaluation of newly designed reinforced bamboo scrimber composite beams. Constr Build Mater 143(7):61-70. https://doi.org/10.1016/j.conbuildma t.2017.03.052

12. Wei Y, Ji XW, Duan MJ, Li GF (2017) Flexural performance of bamboo scrimber beams strengthened with fiber-reinforced polymer. Constr Build Mater 142(7):66-82. https://doi.org/10.1016/j.conbuildmat.2017.03.054

13. Li HT, Wu G, Zhang QS, Deeks AJ, Su JW (2018) Ultimate bending capacity evaluation of laminated bamboo lumber beams. Constr Build Mater 160(1):365-375. https://doi.org/10.1016/j.conbuildmat.2017.11.058

14. Wei Y, Zhou MQ, Chen DJ (2015) Flexural behaviour of glulam bamboo beams reinforced with near-surface mounted steel bars. Mater Res 19(sup1):S1-S98. https://doi.org/10.1179/1432891715z.0000000001377

15. Yan Y, Liu H, Zhang X, Wu H, Yun H (2016) The effect of depth and diameter of glued-in rods on pull-out connection strength of bamboo glulam. J Wood Sci 62(1):109-115. https://doi.org/10.1007/s10086-015-1516-5

16. Auclair SC, Sorelli L, Salenikovich A (2016) A new composite connector for timber-concrete composite structures. Constr Build Mater 112(6):84-92. https://doi.org/10.1016/j.conbuildmat.2016.02.025

17. Martins C, Dias AMPG, Costa R, Santos P (2016) Environmentally friendly high performance timber-concrete panel. Constr Build Mater 102(2):1060-1069. https://doi.org/10.1016/j.conbuildmat.2015.07.194

18. Boccadoro L, Zweidler S, Steiger R, Frangi A (2017) Bending tests on timber-concrete composite members made of beech laminated veneer lumber with notched connection. Eng Struct 132(2):14-28. https://doi. org/10.1016/j.engstruct.2016.11.029

19. Tannert T, Endacott B, Brunner M, Vallee T (2017) Long-term performance of adhesively bonded timber-concrete-composites. Int J Adhes Adhes 72(1):51-61. https://doi.org/10.1016/j.jjadhadh.2016.10.005
20. Kozma A, Odenbreit C, Braun MV, Veljkovic M, Nijgh MP (2019) Push-out tests on demountable shear connectors of steel-concrete composite structures. Structures. https://doi.org/10.1016/j.istruc.2019.05.011

21. Katwal U, Tao Z, Hassan MK (2018) Finite element modelling of steelconcrete composite beams with profiled steel sheeting. J Constr Steel Res 146(7):1-15. https://doi.org/10.1016/j.jcsr.2018.03.011

22. Lasheen M, Shaat A, Khalil A (2018) Numerical evaluation for the effective slab width of steel-concrete composite beams. J Constr Steel Res 148(9):124-137. https://doi.org/10.1016/j.jcsr.2018.05.015

23. Song A, Wan S, Jiang Z, Xu J (2018) Residual deflection analysis in negative moment regions of steel-concrete composite beams under fatigue loading. Constr Build Mater 158(1):50-60. https://doi.org/10.1016/j.conbu ildmat.2017.09.075

24. Tian LM, Kou YF, Hao JP (2019) Axial compressive behaviour of sprayed composite mortar-original bamboo composite columns. Constr Build Mater 215:726-736. https://doi.org/10.1016/i.conbuildmat.2019.04.234

25. Shan B, Xiao Y, Zhang WL, Liu B (2017) Mechanical behavior of connections for glubam-concrete composite beams. Constr Build Mater 143(7):158-168. https://doi.org/10.1016/j.conbuildmat.2017.03.136

26. Wei Y, Ji XW, Zhou MQ, Zhao LL, Duan MJ (2017) Mechanical properties of bamboo-concrete composite structures with dowel-type connections. Trans Chin Soc Agric Eng 33(3):65-72. https://doi.org/10.11975/j.i ssn.1002-6819.2017.03.009 (in Chinese)

27. Wei Y, Li N, Wu G, Duan MJ, Li GF (2017) Load-slip behavior of perforated plate connections of bamboo-concrete. J Southeast Univ 47(6):11671173. https://doi.org/10.3969/j.issn.1001-0505.2017.06.014 (in Chinese)

28. Wei Y, Zhou MQ, Ji XW, Duan MJ, Li GF (2017) Flexural performance of composite bamboo-concrete beams. J Southwest Jiaotong Univ 52(6):1148-1151. https://doi.org/10.3969/j.issn.0258-2724.2017.06.015 (in Chinese)

29. Ding LN, Xia L, Xin W, Jiao HH, Shen WZ (2018) Mechanical properties of pultruded basalt fiber-reinforced polymer tube under axial tension and compression. Constr Build Mater 176(7):629-637. https://doi. org/10.1016/j.conbuildmat.2018.05.036

30. Wang LB, Wu Y, Noori M (2015) Parameters of static response of carbon fiber reinforced polymer (CFRP) suspension cables. J Cent South Univ 22(8):3123-3132. https://doi.org/10.1007/s11771-015-2849-3

31. Zhang YX, Peng H, Lv WH (2018) Shear stress transfer model for evaluating the fracture behaviour of SHCCs for RC shear strengthening. Mag Concr Res 70(10):1-7. https://doi.org/10.1680/jmacr.17.00104

32. ASTM D143-09 (2009) Standard test methods for small clear specimens of timber. Pennsylvania, USA

33. Gutkowski R, Brown K, Shigidi A, Natterer I (2008) Laboratory tests of composite wood-concrete beams. Constr Build Mater 22(6):1059-1066. https://doi.org/10.1016/j.conbuildmat.2007.03.013

\section{Publisher's Note}

Springer Nature remains neutral with regard to jurisdictional claims in published maps and institutional affiliations.

\section{Submit your manuscript to a SpringerOpen ${ }^{\circ}$ journal and benefit from:}

- Convenient online submission

- Rigorous peer review

- Open access: articles freely available online

- High visibility within the field

- Retaining the copyright to your article

Submit your next manuscript at $\boldsymbol{\nabla}$ springeropen.com 